\title{
Verónica Haydeé Torres
}

Facultad de Ciencias Políticas y Sociales. Universidad Nacional de Cuyo. Argentina

veronicahaydee2002@yahoo.com.ar

\section{LO VISUAL SE SUMA: UNA MIRADA SOBRE INSTAGRAM Y SU USO EN LA CAMPAÑA NACIONAL POR LA LEGALIZACIÓN DEL ABORTO ENTRE 2018-2019}

\begin{abstract}
Resumen: Las redes sociales permitieron que las luchas de los movimientos sociales fueran globales, accesibles e interconectadas. Instagram permite la circulación de las miradas sobre el mundo a través de imágenes, fotografías y videos y la participación de sus usuarios/as en la creación de un discurso visual. Este artículo pretende describir la incorporación del filtro como pañuelo verde y el uso del color emblemático de la Campaña Nacional por el aborto en Argentina en publicaciones a modo de ejemplo desde una mirada multimodal que realizaron en Instagram en sus cuentas colectivos feministas asociados como@abortolegalmza entre 2018 y 2019. El uso del pañuelo verde como filtro y el empleo de los colores emblemáticos posiblemente crearon una marca que permitió el compromiso de jóvenes y adolescentes con los ejes de la Campaña. Así, lo visual en las redes sociales fue el mensaje y el medio por el cual los colectivos feministas en Argentina (entre el 2018 y 2019 y hasta la actualidad) propusieron nuevas prácticas discursivas.
\end{abstract}

Palabras clave: Instagram, aborto, militancia,imagen, color

The visual is added: a look at Instagram and its use in the national Campaign for the legalization of abortion between 2018-2019

\begin{abstract}
Social media allowed the struggles of social movements to be global, accessible and interconnected. Instagram allows the circulation of views on the world through images, photographs and videos and the participation of its users in the creation of a visual discourse. This article aims to describe the incorporation of the green scarffilter and the use of the emblematic color of the National Campaign for Abortion in Argentina in publications as an example from a multimodal view that were made on Instagram in their associated feminist collective accounts such as @abortolegalmza between 2018 and 2019. The use of the green scarf as a filter and the use of the emblematic colors possibly created a brand that allowed the commitment of young people and adolescents with the axes of the Campaign. Thus, the visual in social networks was the message and the means by which feminist groups in Argentina (between 2018 and 2019 and up to the present) proposed new discursive practices.
\end{abstract}

Keywords: Instagram, abortion, militancy, image, color 


\section{Introducción}

Este artículo pretende revisar las potencialidades materiales de Instagram como red social exclusiva de lo visual, con el uso de fotografías, videos e imágenes y usada, en su mayoría por adolescentes y jóvenes. Dicha potencialidad ha sido explotada por la Campaña Nacional por el derecho al aborto legal en Argentina durante las convocatorias en hitos específicos como la extensa lucha por la aprobación del proyecto de ley de la interrupción voluntaria del embarazo (IVE) en Argentina, y específicamente en Mendoza, entre el 2018 hasta su sanción a fines de 2020. De este corte temporal, el interés de este trabajo es la utilización de filtros a los que convoca la misma red social y que es aprovechada por jóvenes en el marco de la Campaña, como parte de la construcción de una gramática visual digital y que es una de las extensiones del activismo en el escenario urbano. Además, en términos visuales, la incorporación de los colores a un sintagma de carga ideológica y su posterior inclusión en las redes sociales, nos muestra cómo las potencialidades, materialidades y discursos de redes como Instagram develan otros escenarios de activismo, más acordes al contexto de la web 2.0.

El color verde aborto, el pañuelo como objeto símbolo y las propias particularidades de Instagram muestran la incorporación de lo visual en un nivel de abstracción discursiva que desborda el reclamo de las agrupaciones feministas hasta volverse una demanda colectiva que ha unido a generaciones de mujeres argentinas, desde las históricas luchadoras hasta la marea verde.

Los datos para este trabajo son anteriores al contexto de pandemia y se han tomado de los informes de libre acceso aportados por We are social Hootsuite y, aunque, se han incorporado cifras actuales (2021), esta interpretación se limita a estos dos aspectos: la potencialidad de Instagram en la relación usuario-convocatoria en el uso del filtro de color verde y el peso simbólico del color en 2018 y 2019 desde la semiótica multimodal.

Es importante aclarar que la reflexión sobre las características de Instagram y su uso en el reclamo por la IVE es previa a la pandemia por COVID-19, ya que el marco de globalización del coronavirus cambiará totalmente la forma del activismo por la IVE durante el 2020. 


\section{Contexto}

En el 2005 nace la Campaña Nacional por el derecho al aborto legal, seguro y gratuito (Maria Alicia Gutiérrez:2019) Durante 15 años se presentarán proyectos de ley que tendrán su punto de máximo de acercamiento en el 2018 entre los meses de junio y agosto. En febrero de 2020 una vez más se realiza la presentación con el aval de legisladores y legisladores afines a la demanda y el 1ero de marzo de 2020, el gobierno nacional anuncia a través del presidente Alberto Fernández que la gestión propondrá su propio proyecto de ley.

La Campaña fortalecerá su política expansiva con el uso de las redes sociales a través de las cuales expandirá su campo de acción con producciones de videos, fotogalerías y flyers con información de las acciones realizadas en el territorio argentino. En estas producciones el simbólico color verde, el pañueloy los lemas se volverán parte de su marca de identidad. La Campaña dentro de sus estrategias de militancia hará uso de herramientas digitales no sólo para informar sino para entrar en ese nuevo territorio virtual: el de las redes sociales y sobre todo en aquellas en las que la llamada marea verde se siente más identificada como audiencia por particularidades de consumo, edad y posibilidades de explotación y uso.

Figura 1: Prensa spot Regional Mendoza-Campaña Nacional. Spot 1 Regional Mendoza A 15 años de la Campaña Nacional por el derecho al aborto.

En ocasión de los 15 años de la Campaña Nacional por el Derecho al Aborto Legal, Seguro y Gratuito, la Regional Mendoza realiźó una serie de spots que publicó en sus redes para desmitificar y seguir exigiendo jaborto legal ya!

Cuando hablamos de aborto debemos entender la diferencia entre despenalizar y legalizar

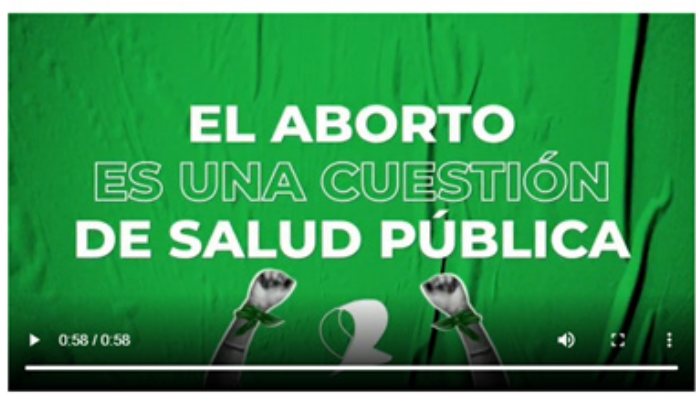

Fuente: Recuperado de: http://www.abortolegal.com.ar/wpcontent/uploads/2020/08/video_2020-08-26_00-28-23-1.mp4.

La Ley de Interrupción Voluntaria del Embarazo (IVE) No 27.610 de Argentina fue sancionada por el Congreso Nacional el 30 de diciembre de 2020 y promulgada el 14 de enero de 
2021. Fue aprobado en la Cámara de Diputados por 131 votos afirmativos y 117 negativos, y en la Cámara de Senadores por 38 votos a favor y 29 en contra.

En la madrugada del 30/12/2020 el Congreso Nacional aprobó la Ley de Interrupción Voluntaria del Embarazo con la Ley de los Mil Días como parte de un sistema nacional de atención y cuidado integral de la salud durante el embarazo y la primera infancia.

La aprobación de la IVE culmina el esfuerzo multitudinario de las mujeres y se sanciona en respuesta a los años de luchas de los colectivos feministas. En el XIX Encuentro Nacional de Mujeres (Mendoza:2004) se había iniciado la Campaña Nacional por el Derecho al Aborto Legal Seguro y Gratuito.

Para las militantes, activistas y adherentes, en general, el lema de la Campaña se convierte en el eje de la lucha: «Educación sexual para decidir, anticonceptivos para no abortar, aborto legal para no morir»-Luego de varios intentos para presentar el proyecto de ley desde el 2007, el punto épico ocurre entre junioy agosto del 2018 que no logra su aprobación por escasos votos; había sido rechazada en el Senado (38 senadores en contra y 31 a favor). Sin embargo, no fue un suceso que desalentó a la Campaña y se volvió a presentar en marzo de 2020, el año de su sanción.

\section{Figuras 2 y 3: Vigilia en Plaza Independencia (29/12/2020)}

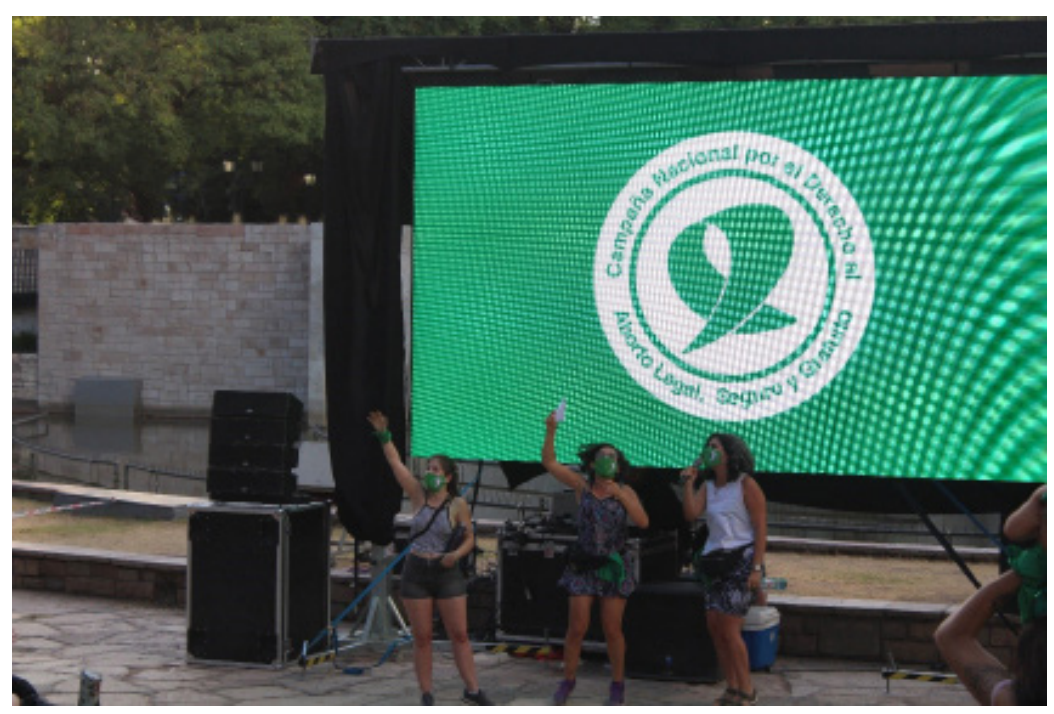




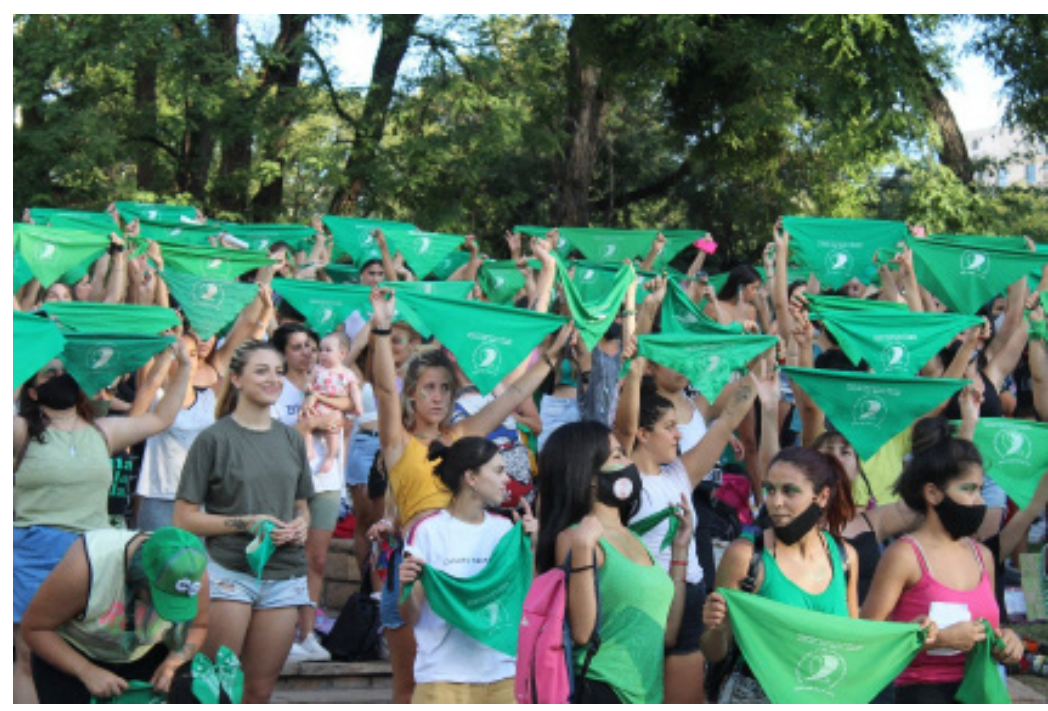

Fuente: fotografías tomadas por Verónica Torres. Publicado el 30/12/2020 en Facebook: https://www.facebook.com/ observatoriodemediosdelodiscursivoalosocial

\section{Un cambio de mirada atravesado por las tecnologías: la web 2.0}

La antropóloga y comunicadora Paula Sibilia (2017) explica en claves genealógicas los cambios culturales que evidencian nuestros comportamientos sociales en el impacto de la web 2.0 no sólo en lo tecnológico sino también en una forma de percibir/percibirse en un estar siendo en las redes sociales.

Como síntesis de estas claves, Sibilia señala que en el actual contexto existe un modo de ser y estar en el mundo dentro del contexto de la convergencia (tecnologías digitales y portátiles de información y comunicación) que se manifiesta en el uso de las redes sociales y en el cual somos habitantes de sociedad globalizada siglo XXI y tecnología digital ya que vivimos en compatibilización con los dispositivos (celulares PC individual, tablets) y a través de estos en permanente acceso a la red; lo que nos lleva a que en cierta manera, nuestro modo de vivir sea en modo visible y en contacto con cantidades crecientes de personas con las cuales nos establecemos en comunidades, es decir que nos construimos en esa compatibilización.

Dentro de las situaciones problemáticas que analiza, la web 2.0 permitiría nuestra ubicuidad y temporalidad (en todo lugar/en todo momento) con lo cual se desarma con el uso de 
las pantallas lo que se concebía en el siglo XX como privacidad. Sibilia usa la metáfora de la pared asociada a los espacios privados (en términos espaciales, la localización de un lugar, habitación/recámara/suite/alcoba/cuarto como símbolo de la intimidad cerrada por paredes para desarrollar la subjetividad y la introspección. éste es un concepto que corresponde a la idea de la modernidad en los siglos XVIII XIX y XX y tiene su correlato en lo analógico. Actualmente, estaríamos en tensión con la no privacidad (lo digital) la exposición como un modo de vivir enredados: en la interacción, publicación, posteo, etc.

Esto explicaría la existencia de una multicausalidad de la ruptura histórica entre lo analógico y lo digital que permitiría definir a nuestra sociedad como líquida/ espectacular/postindustrial a la que Sibilia ubica en el contexto de la contemporaneidad. Se observa así esta tensión entre las tecnologías digitales y las analógicas porque estas herramientas tecnológicas no son neutrales, pero sí históricas; y en su uso se muestran los valores de su época. Los artefactos se pueden usar, pero no para cualquier cosa: la herramienta determina un modo de vivir y un uso implicado. Como ejemplo, los diarios íntimos del siglo XIX y XX estaban vinculados a la subjetividad en la intimidad y lo privado de las paredes; el blog, una cuenta de Instagram para que sea público, se exponga, se exhiba, se muestre, se comparta). Como ejemplo de ello, es el fenómeno de la hipersexualidad de la mujer que deja fronteras difusas entre ser audaz y dueña de su sexualidad y la tendencia y un intrincado sustrato discursivo machista con las llamadas sexygrammers que deriva en las sexygrammers adolescentes que producen sus propias selfies con poses eróticas. Básicamente son usuarias de Instagram que muestran en sus cuentas principalmente fotos de ellas mismas en actitudes más o menos erotizadas. Las sexygrammers adultas a su vez suelen estar sostenidas por discursos mediáticos del tipo "X" encendió Instagram con fotos.

Sibilia se pregunta en este contexto ¿cómo están cambiando nuestros modos de vivir tras haber adoptado las herramientas digitales para realizar cada vez más actividades? Para responder esto se basa en el concepto de Guy Debois: la espectacularización del Yo. Hay una transformación del concepto de la subjetividad atravesado por la nueva dimensión de ubicuidad que permite esta performatividad y su espectacularización: es decir, un modo de ser y de ser 
valorado a través de la mirada de una audiencia con la que se interactúa a través de las redes sociales. Dicha extimidad de lo que antes estaba encerrado en las paredes (lo privado/ íntimo) no solo habla de esta nueva subjetividad alterdirigida sino también de la imposición de nuevos estándares estéticos del culto al cuerpo, y aún esos que aparentan rebelarse ante las normas, son tomadas por las corporaciones y reinsertadas en el mercado construyendo un nuevo relato del cuerpo acorde aun con las mismas demandas y manifiestos de los nuevos movimientos emergentes y de las diversidades sexuales y culturales.

Esta forma de vivir en la mirada del otro será, según Sibilia, una forma de estar y ser de las generaciones más jóvenes como millennials, los $\mathrm{Z}$ y las más recientemente incorporadas.

Por ello, el cruce tecnológico y cultural definirá la forma de vivir y de relacionarse. En este recorte de la realidad, existe una forma de relacionarnos y de comunicarnos, es decir, de construirnos socialmente y esto ha sufrido transformaciones desde la expansión y uso de las redes sociales.

Compartimos nuestro mundo, ideas, gustos y nos definimos frente a otros en lo que elegimos, seleccionamos o mostramos. La relación entre las redes sociales y quienes se construyen a través de ellas también define en el lugar que éstas ocupan en la vida de sus usuarios. Entre los adolescentes, por ejemplo, una red social no sirve para comunicarse, es ella la que en su modo de ofrecer la interacción con otros pares oficia de dimensión existencial; un estar siendo en internet ya que permite interactuar, comunicar, acceder y mostrar. El personaje de Verónica, por ejemplo, en la comedia de Netflix Sierra Burgess Is a loser (2018) no destaca ni por sus notas ni cuenta con un extenso currículum, pero si es experta en sacar fotos y subirlas a su cuenta. Sabe contar mostrando; sus historias se forman con el plano adecuado y el ángulo que explota visualmente un objeto, una figura; la gestualidad, la pose, los colores y luz, es decir, la composición de una imagen que parte de un contrato entre quien produce la imagen y quien la avala con sus comentarios, menciones o posteos. En esta comedia, se observan dos estereotipos femeninos: Sierra es una estudiante dedicada, hija de un matrimonio afectuoso, pero fuera del canon estético impuesto en este mundo imaginario del colegio secundario y no es una chica popular; en contraste, está Verónica, popular, alumna de bajo 
rendimiento y cuya familia es disfuncional, representa todo lo que es una adolescente instagrameable (en la categoría que usa Paula Sibilia: 2017) que sabe usar las redes sociales y explotar las posibilidades materiales de la cámara del celular y de conocedora de la estética visual de la fotografía en este mundo para ser mirado: luz, ángulo, plano y pose.

\section{Instagram: la red de adolescentes}

Instagram una de las redes sociales on line más populares entre los y las jóvenes que a partir de una aplicación que se puede instalar fácilmente en un celular permite subir fotografías y videos con los que se arman historias que no duran más de 24 horas o describen quien es el dueño de esa cuenta según lo que sube o replica. Es fácil de usar, accesible, gratuita y permite vinculaciones con otras redes sociales como WhatsApp, Facebook y funciona también para chatear entre quienes están conectados a partir de la función: seguir una cuenta sugerida o un perfil propuesto por Instagram a partir de una selección de gustos, intereses, publicaciones y posteos.

Sean cuentas públicas o privadas (con el requisito de aceptar ser un seguidor de la cuenta) le ofrecen al titular el control sobre comentarios, fotografías y menciones de otros "internautas" si no son de su agrado, ya que pueden bloquear a otros usuarios, entonces, éstos no podrán ni acceder a sus publicaciones ni interactuar con dicho sujeto.

Las historias (stories) se identifican rápidamente a través de etiquetas marcadas con el uso de hashtasg (\#) y cuya posibilidad de edición de las imágenes que se comparten será una de sus particularidades en competencia con otras redes sociales.

Instagram es una red social y una aplicación para subir fotos y videos. Más allá de lo que los expertos denominan el sistema de recompensa (los likes y comentarios de fotos yvideos) y promoción de los usuarios a través de sus publicaciones que explicarían en parte su popularidad a través de estas imágenes que como hemos mencionado permiten procesos de edición y etiquetado. Instagram fue, en parte, una de las herramientas más usadas por la Campaña Nacional por el Aborto Legal y los colectivos feministas que están asociadas a ella y en contacto con otras agrupaciones con las que se compartió el ideario básico de esta institución en relación a la legalización y despenalización del aborto. 
Estas herramientas digitales, empleadas por la Campaña y parte de las potencialidades de Instagram, permitieron expandir el radio de acción, compartir información y unificar el discurso visual y lingüístico de ciertos actores sociales específicos que defendían una posición política a favor de la IVE. Es decir, se transformó en uno de los medios digitales utilizados en las operaciones de activismo social por la IVE y posibilitó identificar los ejes de la Campaña e interactuar con sus seguidores/as como titular de la cuenta.

La incorporación de la presencia en Instagram de la cuenta de la Campaña Nacional por el Aborto Legal (CNAL) implicó un movimiento de reconocimiento de las nuevas formas de comunicación (las condiciones que permiten tecnológica y culturalmente las redes sociales, por ejemplo, el uso de filtros y de la participación de influencers) de quienes han sido considerados sus seguidores (followers) usuarios (adolescentes y jóvenes que formaban parte de la marea verde) y de la inclusión de su uso dentro de las estrategias de activismo social, ahora virtual.

En cuanto al uso de plataformas y redes sociales por parte de colectivos y agrupaciones, es menester, distinguir algunos conceptos como militancia digital, ciberactivismo y activismo. Para los fines de esta publicación, se prefiere el término: activismo digital. Según Natalia Aruguete y Calvo (2020) el comportamiento en las redes sociales de las comunidades o "nodos" interactúan a partir del debate político, social y cultural desde frammes (marcos) cognitivos y motivados emocionalmente frente a representaciones ideológicas que fuerzan frente a temas públicos y políticos a posicionarse.

Esto manifiesta la tendencia de las discusiones y esos comportamientos pueden estar al mismo tiempo asociados en algunos de esos nodos con activismo.

Por otra parte, se pueden detectar sujetos colectivos como agrupaciones y colectivos definidos, que los que convocan a realizar una acción específica como twittazos, por ejemplo.

Las redes sociales se han convertido en el escenario de la protesta de las mujeres. A través de campañas de tecnopolítica, el feminismo proporcionó marcos interpretativos (frames) que activaron un intenso proceso de discusión pública sobre la violencia de género y la necesidad de contar con una ley que despenalice el aborto. Esos marcos crearon una nueva narrativa que tuvo a las palabras violencia, derechos, 
lucha, libertad e igualdad como protagonistas de una nueva y esperanzadora discursividad (Marina Acosta, 2018).

Se redefinen así las formas del activismo local en Argentina que posteriormente o de manera simultánea por los propios procesos de globalización que la web 2.0 permiten se extienden a otros países.

Demaneraorganizadaycon un fuertecarácteridentitario, el uso de las redes sociales como un escenario que se suma a la militancia y cuyas herramientas permitirán la irrupción de sujetos colectivos e individuales, el ciberactivismo también será una práctica de los movimientos sociales urbanos emergentes o la reconversión de los ya existentes, como el feminismo, tal como señalan Sierra Caballero y Solá-Morales (2020) $)^{1}$.

Así, el uso de Instagram permitiría ver a la red social como lugar de encuentro, interacción y de construcción de un relato: la gran historia (storie), en este caso: la lucha por la IVE en cada rincón de Argentina entre 2018 y 2019.

\section{Instagram: características}

Kevin Systrom y Mike Krieger crearon Instagram en el 2010 y alcanzó más de cien millones de usuarios activos en el 2012 y trescientos en 2014. Se puede usar en dispositivos Ios y Android y en el 2016 para Windows 10. Actualmente cuenta con más de 900 millones de usuarios activos². En Argentina, en el 2018, existían ya 39,9 millones de usuarios únicos de celulares según un Informe de Mobile Regional Insights ${ }^{3}$ y el $87 \%$ de la población accedía a Internet sólo a través de sus dispositivos, lo que permite visualizar el potencial de Instagram en función de los intereses de la CNAL en el contexto de los debates por el proyecto de ley de legalización del aborto entre junio y agosto de ese mismo año.

Cristina Madrigal Romero (2015, p. 8) plantea que Instagram a diferencia de otras redes sociales genera un mayor compromiso entre producto, medio y usuario; este engagement (compromiso), parte del uso de la imagen y lo visual como punto fuerte de la misma por lo cual, transforma lo que propone en su aplicación, en un potencial uso de promoción no invasivo.
1 Sobre activismo digital en Facebook y Twitter en Argentina acerca del \#NUM (Ni Una Menos) y de la viralización del hasthag \#vivasnosqueremos, veasé el trabajo de Claudia Laudano (2019) que describe el proceso de construcción del fenómeno en las redes sociales en 2015 (Laudano, 2019).

2 Instagram: En https:// es.wikipedia.org/wiki/ Instagram Consultado el 30 de marzo de 2020.

\footnotetext{
${ }^{3}$ Argentina es el país de la región que tiene más smartphones por habitante. En https://www.baenegocios. $\mathrm{com} /$ negocios/Argentinaes-el-pais-de-la-region-quetiene-mas-smartphones-porhabitante-20180129-0022.html
} 
${ }^{4}$ ¿Qué redes sociales prefieren los argentinos según su edad? En https://www.digitalhouse.com/ ar/noticias/que-redes-socialesprefieren-los-argentinos-segunsu-edad- marketing

${ }^{5}$ Las redes sociales más usadas por los argentinos. En https://www. digitalhouse.com/ar/noticias/lasredes- sociales-mas-elegidas-losargentinos-marketing-digital

6 https://yiminshum.com/socialmedia-argentina-2020/

7 https://wearesocial.com/ blog/2020/01/digital-2020-3-8billion-people-use-social-media

\section{Figura 4: Red social por generación}

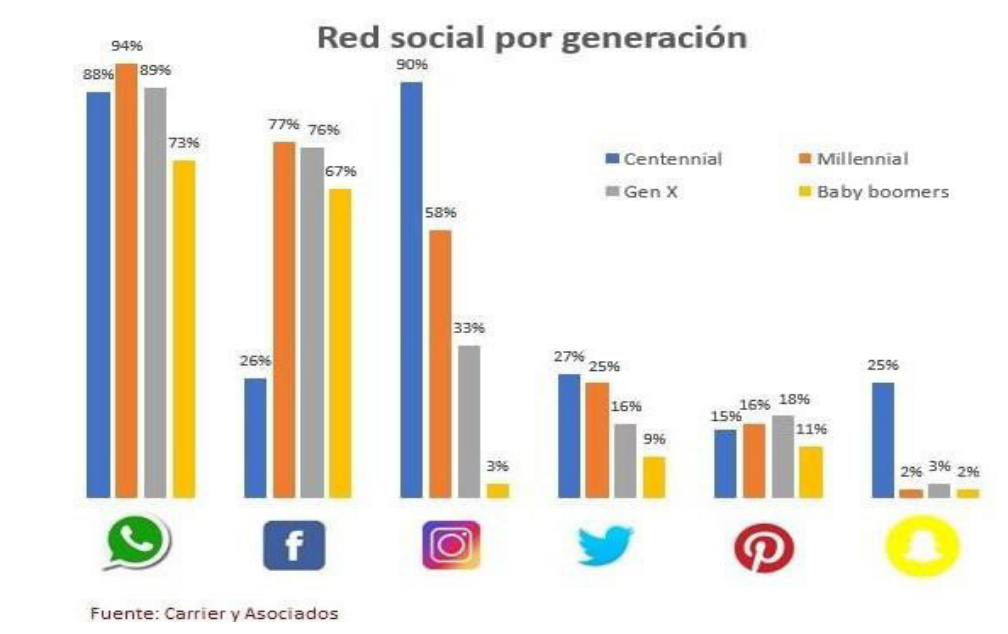

Fuente: Recuperado de: https://www.digitalhouse.com/wpcontent/uploads/2018/08/unnamed-4.jpg

Según los datos obtenidos por la consultora Carrier, el corte etario que consume Instagram es entre el 80 y $90 \%$ corresponde a los grupos centennial y millennial, quienes demográficamente corresponden a las generaciones dentro de las que se ubican los colectivos que militan en el campo de lo virtual la Campaña Nacional. Al mismo tiempo, está consultora agrega que Instagram al igual que otras redes tiene una curva de aprendizaje empinada que desalienta a quien no está familiarizado con la misma, entre el 2017 y 2018 tiene un incremento del 16\% de usuarios en Argentina transformándose en la 2 da red social elegida en nuestro país ${ }^{5}$.

En Situación digital, Internet y redes sociales: Argentina 2020 (16/03/2020) publicado en el sitio Yiminshum ${ }^{6}$ se recuperan los datos que We are Social ${ }^{7}$ ha recolectado sobre usos de plataformas, tiempo y perfil de audiencia con un claro objetivo de Marketing y Publicidad. En marzo del 2020, en Argentina existen 35 millones de usuarios de internet y 34 millones de usuarios activos en redes sociales y aumentó un 7 $\%$ en el último año. Además, más del $94 \%$ utilizan dispositivos móviles en estas interacciones: 78 \% Smartphone y el $15 \%$ de celulares sobre PC, tablets y computadoras personales. Instagram como red social tiene 89.920 .00 usuarios en movimiento.

Este incremento que subraya We Are Social, refleja para Madrigal Romero (11) una migración de comportamiento en las que pasan de una sola a diversificarse en varias redes, otros a utilizar menos e incursionar más en otras que más a tono con la tendencia general; algunos mudan de Facebook 
a Instagram, por ejemplo, y con ello de las corporaciones de publicidad y marketing. Madrigal Romero (2015) señala que:

Desde una perspectiva global, lo que se observa como tendencia es que las personas están migrando en sus comportamientos online. El incremento de audiencias en las redes, no se debe tanto al acceso de nuevas personas, sino a que la población online está usando más redes, varios dispositivos para ingresar, pasan más tiempo en internet y están llevando a cabo un número creciente de actividades (algunas que hasta ahora hacían offline).

Los móviles están creciendo rápidamente como primer dispositivo para acceder a las redes sociales. Pero no se abandona ningún dispositivo. La tendencia multidispositivo está caracterizando el uso de internet a nivel global, y obliga a pensar estrategias crossplataforma (2015, p.11).

En la medida en que se va imponiendo esta nueva tendencia del multidispositivo también se va familiarizando e instalando una forma de comunicación visual. Esta web visual señala Madrigal Romero (2015) se desarrolla a partir de los procesos de percepción y la elaboración de la información a partir de las imágenes.

Es decir, lo visual se vuelve parte de lo que se comparte e informa, y suma la posibilidad de participación para los usuarios a través fotos e imágenes editadas y producidas de manera sencilla e intuitiva con lo que se genera un vínculo a través de lo emocional. Estas serían las ventajas de redes sociales como Instagram.

Entre las características de Instagram, Madrigal Romero (2015) señala que Instagram es una red social profundamente visual que nace para compartir fotografías (propias o compartidas) y que a través de imágenes se relaciona e interviene en la cotidianidad de los usuarios la convierte en una de las más accesibles y usadas. Las historias (story: videos cortos que duran sólo 24 horas), la mensajería y los perfiles de videos y fotos, propone un tipo de relación entre los usuarios y les permite interactuar.

Los \# (hashtags), los likes (me gusta) y la posibilidad de su aplicación en los dispositivos móviles con tecnología IOs, Android más su incorporación asociada a otras redes como Facebook, vuelven a Instagram en fructífero campo de activismo social también. 


\section{Instagram en cifras}

8 Ver: https://wearesocial. com/digital-2020 y https:// wearesocial.com/digital-2021.
Para consultar los datos mundiales y por país en el uso de redes sociales, la fuente consultada para este trabajo es We are social para 2020 y las tendencias en $2021 .^{8} \mathrm{Al}$ revisar los datos en 2018, 2019, 2020 y la tendencia 2021, algunas cifras explican la expansión, cada vez más asentada, de las cuentas de Instagram. Los datos han sido extraídos de los informes de We are social: Digital 2020 y el Informe sobre las tendencias digitales, ambos elaborados por Hootsuite.

En Argentina, durante el 2020, cerca del 43\% de la población es usuaria de alguna plataforma o red social y ubica al país en el zer lugar en el ranking mundial en el que se elige Instagram. A nivel mundial, el 50,8\% son personas de género femenino y el perfil de usuarios/as de Instagram en Argentina es de más de 13 años disminuyendo pasando los 40 años.

El sector más importante de consumo de alguna cuenta de Instagram, compra en línea o simplemente seguir a un influencer, es entre 18 y 24 años. En el 2019, lo más posteado son videos (5,4\%), fotos e imágenes (4,6\%). En el 2018, en Argentina, con 14 millones de usuarios con acceso a dispositivos móviles (el $31 \%$ de la población total) el $55 \%$ eran mujeres. En el 2020, año de la pandemia, hay un incremento del $6 \%$ de usuarios/as. La tendencia 2021 según We are social es que el nuevo público serán los baby bommers, más tiempo en casa por el aislamiento y ya con iniciados en la experiencia de comprar en línea.

En el ranking mundial, Argentina en cuanto al uso de redes sociales está en lugar 21 y el aumento de usuarios/ as de Instagram es a la par del incremento de usuarios de dispositivos móviles. 
Figura 5: Consumo de Instagram a nivel mundial hasta enero 2020 por edad y género según el informe de We are socialHootsuite.

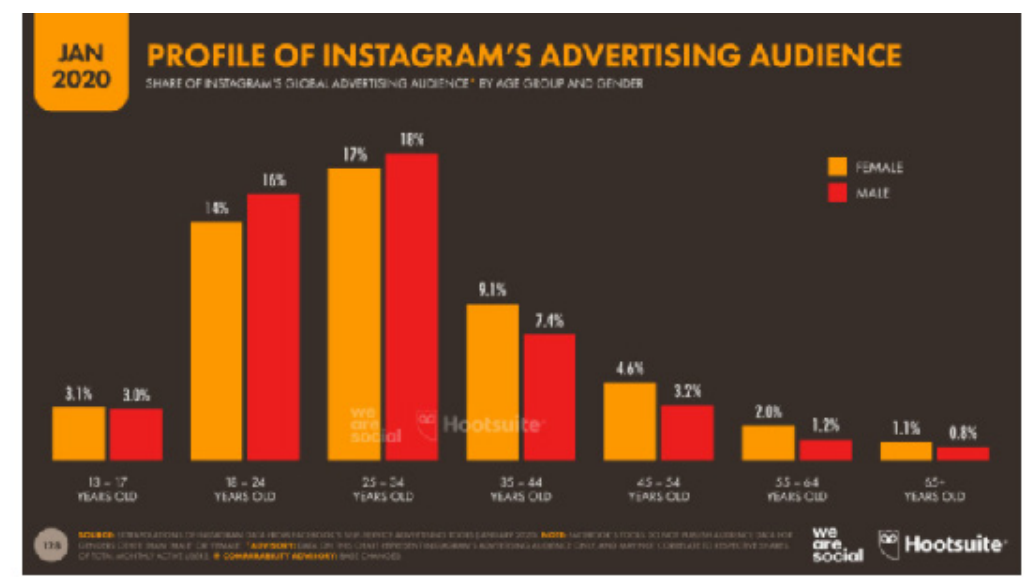

Fuente: Informe We are social-Hootsuite https://wearesocial.com/ digital-2020

Las empresas de marketing se movilizan especialmente en relación a este tipo de informes, puesto que redes sociales como Instagram no sólo movilizan millones de usuarios/as sino que éstos son potenciales nichos de venta de productos y/o servicios. Por un lado, el \#hashtag (Cano, 2020, 25 de diciembre). que se vuelve tendencia, la figura de un/a influencer y el acceso a los dispositivos móviles como parte de una nueva ergonomía humana llevan, como es el caso del 2019, a Instagram a lanzar campañas como el concurso de filtros en sintonía con el marco de la Campaña Nacional por la IVE en Argentina, considerando el incremento de casi un millón de usuarios/as en Argentina de Instagram.

Solo a modo de muestra, un recorte de las publicaciones de la cuenta de Instagram de la Campaña regional Mendoza entre el 29/12/2020 y 30/12/2020 se podrá observar el ritmo de interacción entre usuarios/as y la administración de la misma:

Para este acotado (y limitado) registro de 3 tipos de publicaciones se dejó afuera historias y galerías de fotos y se consideró un flyer oficial, cuatro fotos y un video invitando a la Vigilia en la Plaza Independencia.

- Flyer luego de la votación en el Senado: Es ley con 4982 likes (30/12/2020)

- Foto: Vigilia en la Plaza Independencia (Mendoza) con 2636 likes (30/12/2020) 
- Foto sede General Alvear con 1020 likes (29/12/2020)

- Foto sede San Rafael con 1346 likes (29/12/2020)

- Foto Gran Mendoza: Plaza Independencia con 960 likes (29/12/2020)

- Video convocatoria Venite a la plaza con 2489 likes $(29 / 12 / 2020)$

Figura 6: publicación de la cuenta de Instagram de la Campaña regional Mendoza (abortolegalmza) 30/12/2020. En https://www.instagram.com/abortolegalmza/?hl=es-la
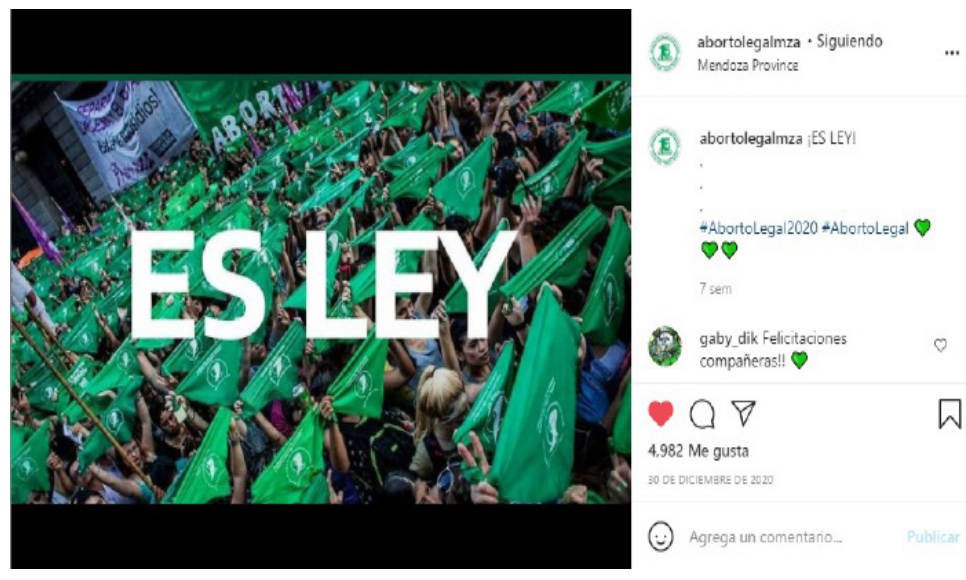

Figura 7: gráfico sobre las 6 publicaciones de abortolegalmza entre el 29/12/2020 y $30 / 12 / 2020$

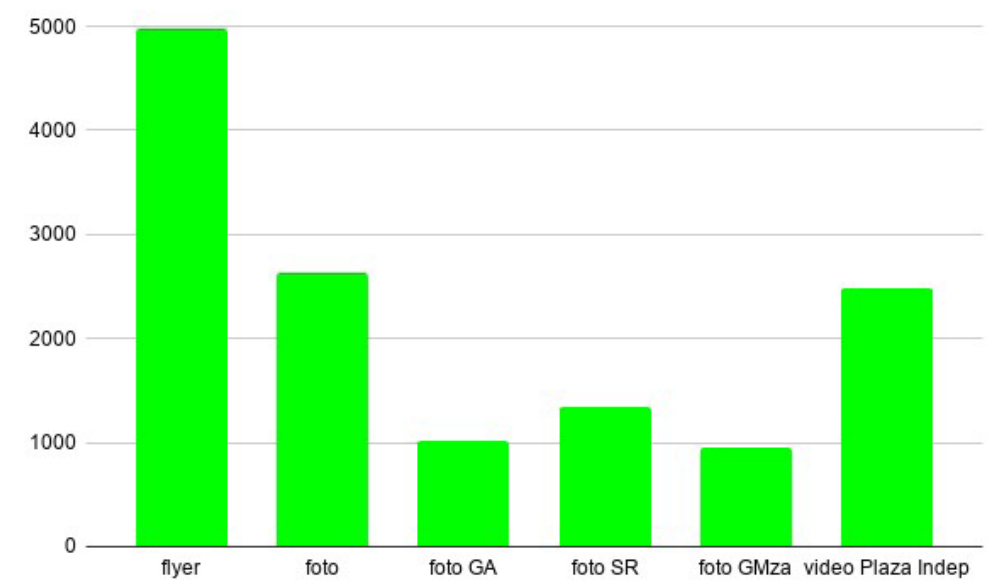

Fuente: Elaboración propia

Para los colectivos dentro del feminismo, como el Plenario de las Trabajadoras (PDT), casi desconocidos para la mayoría femenina fuera del microuniverso del Partido Obrero y en particular, parar la marea verde, por ejemplo, unirse al uso de las cuentas de Instagram y sus potencialidades significativas 
y comunicacionales, esto permitió entrar en el escenario de los debates por el aborto en el 2018 y 2019. Para la Campaña Nacional, y es la una de las hipótesis de este trabajo, fue uno de los escenarios de expansión del activismo. En el 2019, este escenario virtual complementa y acompaña, las acciones en el escenario urbano y en el 2020 , debido a la pandemia y las disposiciones de las políticas sanitariasª será el lugar de las convocatorias y de las acciones.

Figura 8: Convocatoria 18/11/2020 de la cuenta de Instagram abortolegalmza. Convocatoria a Pañuelazo Publicadoel 17/11/2020.

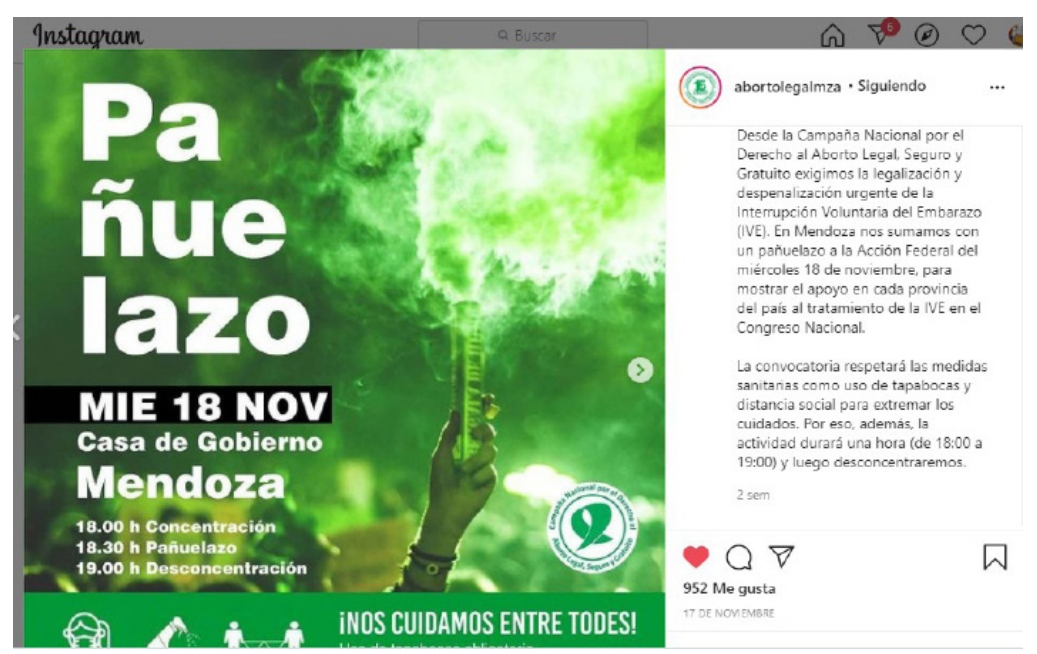

Fuente: Recuperado de: https://www.instagram.com/ abortolegalmza/?hl=es-la

El activismo en pandemia (2020), restringido por las decisiones del ASPO por el COVID-19, tendrá pocas acciones en las calles. La marcha del \#3NUM en Mendoza quedará reducido a un acto y será sólo de un sector en disidencia con parte de la organización del NUM. Un acto con las medidas protocolares de distanciamiento en un frío 3 de junio, las fotos y de ahí a las páginas web, cuentas en las redes sociales y en los grupos de WhatsApp.

\footnotetext{
${ }^{9}$ Aislamiento social preventivo y obligatorio Decreto 297/2020. Consultar en https://www.boletinoficial. gob.ar/detalleAviso/ primera/227042/20200320
} 
Figuras 9 y 10: 3/6/2020-Mendoza (Peatonal Sarmiento, Ciudad de Mendoza) una militante del PDT Mendoza lee el documento por el \#3J.
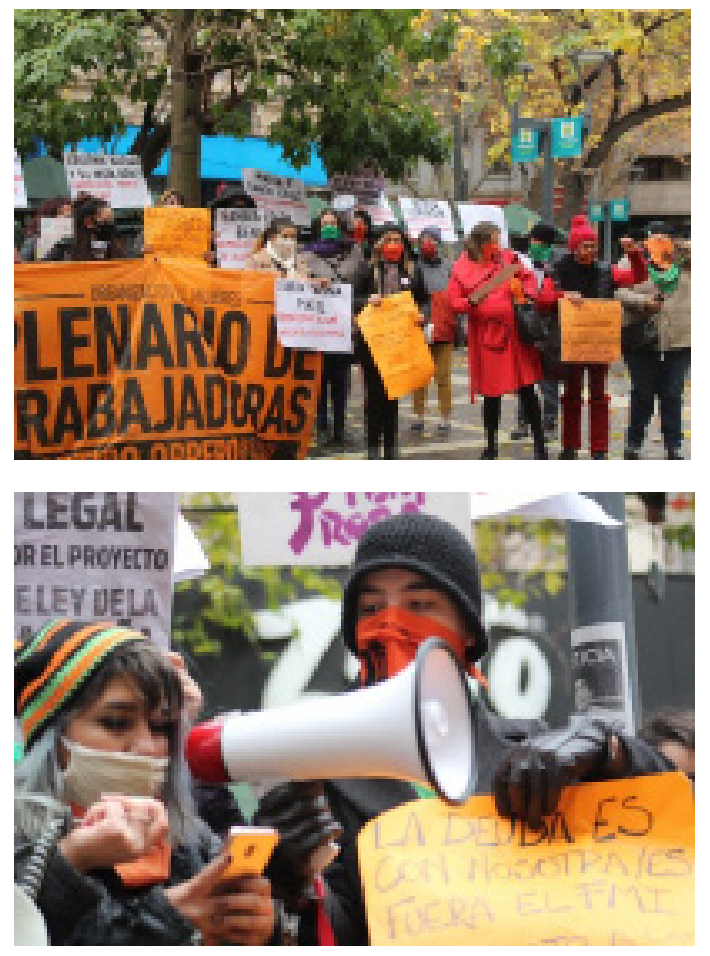

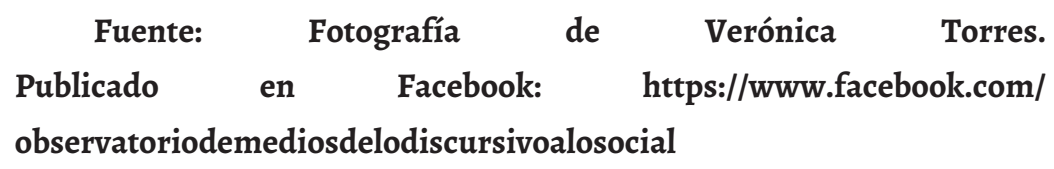

\section{Lo visual en Instagram: filtros e imágenes en la lucha por la IVE}

Las imágenes, en esa forzada sencillez, en ese "posar como si” están intervenidas por los filtros; las sencillas y pequeñas operaciones de edición y el abanico de estos tratamientos de las fotografías le dan un toque de profesionalismo y al mismo tiempo cumplen con esos requisitos de lo instagrameable (Sibilia, Paula, 2019). Como señala Madrigal Romero (22), los filtros funcionan como procesos de intervención y/o manipulación de la imagen conforme a un criterio estético que imponen las tendencias:

Los filtros que utiliza Instagram son alteraciones en las curvas tonales y la saturación cromática de la fotografía que buscan cambiar la a pariencia de la toma original. En definitiva, es utilizado para aportar algún elemento determinado a la foto, para así dotarla de una luz, color o textura diferente. 
Los filtros, sean los que incluye Instagram según el dispositivo que se tenga: un tema tecnológico, los que de que se deseen crear como una marca personal: una definición estética o los de los diseñadores que se utilizan en las stories: el seguimiento del creador y la aplicación, están asociados a los efectos que producen en el tratamiento de la imagen desde la Psicología del Color hasta las saturaciones que producen sus tonalidades (García Nieto:2019).

Heller (2008) señala que sabemos más de sentimientos que de colores pero que cada tonalidad puede trabajar de diferentes maneras provocando distintas reacciones y ello se debe a que ningún color trabaja de manera aislada, siempre están en una relación de complemento, continuidad o contraste. En relación al tema de este trabajo, el verde en la investigación de Heller representa de manera muy general y desde lo cultural desde la fertilidad, la esperanza, el opaco de la burguesía hasta el de los humores y estados de ánimo asociados a la melancolía, la avaricia y la obscenidad.

A este color con una valoración relativamente positiva, se le sumó (sin mayor desarrollo en la investigación de Heller) a una ideología asociada a la defensa del medio ambiente: "conciencia medio ambiental, amor a la naturaleza, y al mismo tiempo, rechazo de una sociedad dominada por la tecnología” (Heller, 2008, p.103)

A diferencia de lo que históricamente se identificaba este significado neutro del verde que señala Heller, surge el llamado "verde aborto" sin cortar posibles asociaciones con el color del medio ambiente y la naturaleza. No es el verde de la muerte sino el verde de un colectivo caracterizado por la lucha de los derechos sexuales y reproductivos asumido también por los grupos etarios más jóvenes: la marea verde. Se agrega otra lectura política: un color que no tenía una carga significativa adquirió un valor simbólico a partir del 2006.

La red social Instagram atenta al contexto del marco de la Campaña y de la emergencia de la marea verde como un nuevo actor realizó una convocatoria a sus usuarios/as: un concurso para la creación con un tutorial de la aplicación de un filtro que identificara todo el movimiento por la IVE en Argentina en el 2019. Surgió así el filtro del pañuelo verde que propuso Instagram a sus seguidores y seguidoras, a través de sus creadores (Scarpini y Mateo, 2019) mantiene un vínculo con el objeto simbólico más fuerte de la Campaña Nacional por el Aborto. 
Más allá que en a lo largo de la historia del movimiento feminista el violeta se había utilizado con este uso ideológico con el que se identificó la lucha por los derechos de la mujer, y cuya vigencia se mantiene como insignia de las feministas, será el verde el que tomará el rol simbólico de los sectores que defienden la IVE y los grupos más jóvenes los llevarán como marca registrada de la marea verde.

El filtro en Instagram de Scarpini y Mateo consiguió más de 3 millones de impresiones en el contexto de la lucha por la legalización de la IVE, empujado por la actriz e influencer Jimena Barón y luego la actriz Carla Peterson que es una de las caras visibles del colectivo Actrices Argentinas (@actricesarg) (Rodrigo Nuñéz:2019). No sólo era el verde seleccionado, el "que se ubica entre el 347 C y el $3415 \mathrm{C}$ de la escala cromática Pantone" (Carolina Muzi: 2019), sino también la forma del pañuelo con su historia política en Argentina.

Figura 11: Escala cromática Pantone Aborto legal, seguro y gratuito.

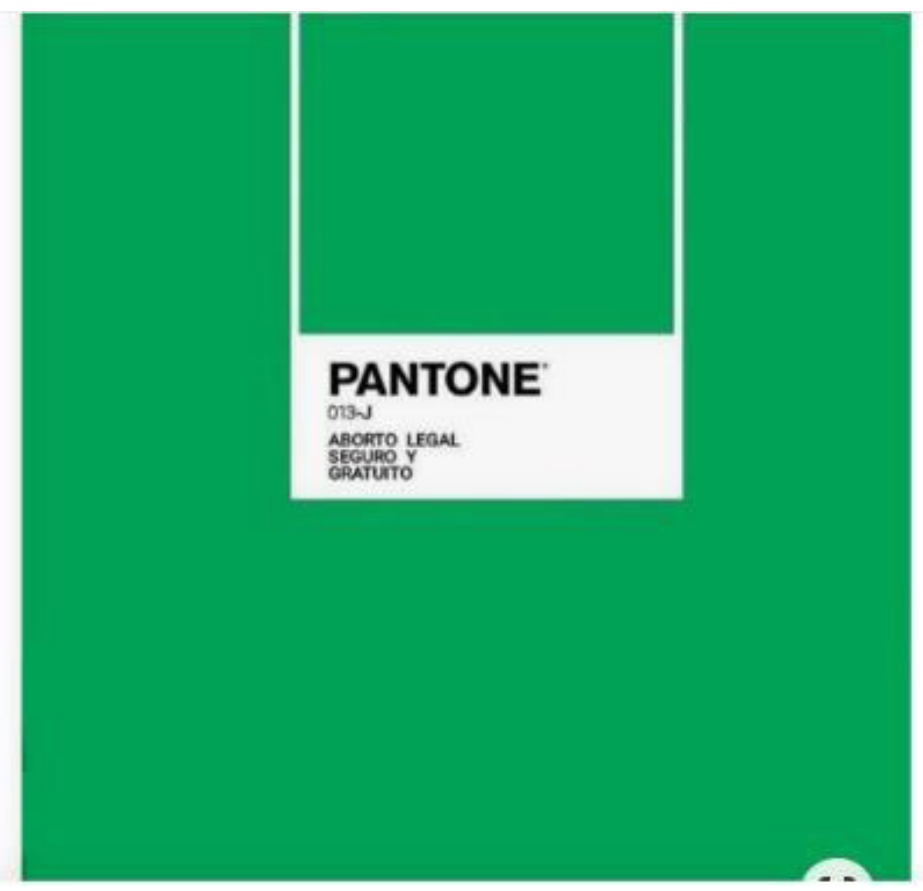

Fuente:https://i.pinimg.com/564x/ca/ff/di/ caffd19225d2847a23b3a8c8ab2dfb99.jpg. Rescatado el 5/12/2020. 
Figura 12: Instagram: crearon un filtro por el aborto legal, seguro y gratuito y se abrió el debate.

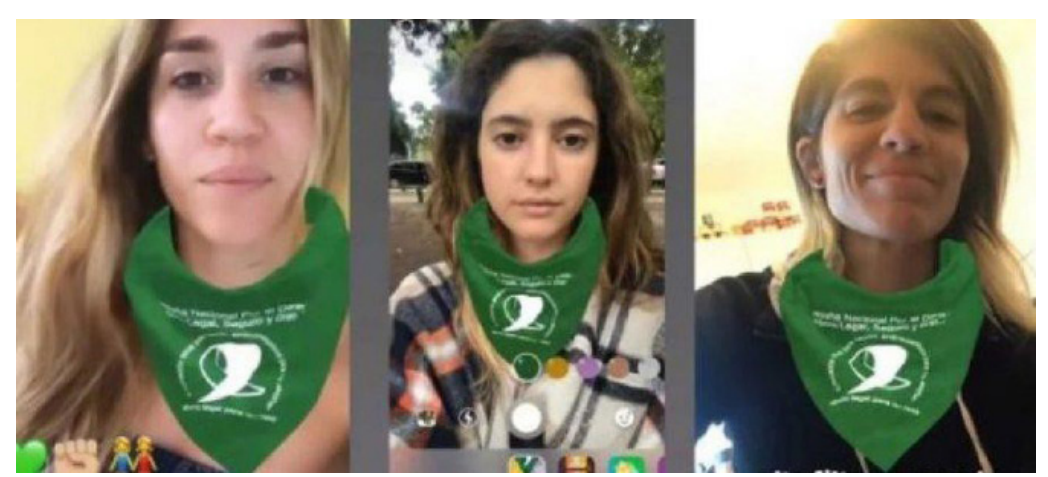

Fuente: Recuperado de: https://diariofemenino.com.ar/ instagram/. Rescatado el 5/12/2020

La actriz Jimena Barón hizo uso de su fuerte presencia en las redes y utilizó el filtro de Scarpini y Mateo, acelerando las impresiones. Lejos de la imagen de militantes feministas, el rol de una influencer será otra de las ventajas de la militancia en lo virtual.

Madrigal Romero menciona entre los efectos delos filtros, a partir de la investigación de Bakhshi, Shamma, Kennedy y Gilbert (2015) que las fotos que son retocadas tienen mejor recepción y eso se manifiesta en los likes de los seguidores. En este caso, el filtro de Scarpini y Mateo se viralizó el 29 de mayo de 2019 y el verde de Pantone es lo que resalta en la foto de la actriz, serán sus seguidores los que harán la promoción de boca en boca según los creadores del filtro.

Los filtros que resaltan los colores cálidos, suben el contraste y la exposición funcionan mejor que los demás. De hecho, utilizar el filtro "correcto" puede aumentar un $21 \%$ las posibilidades de que la foto sea vista y un $45 \%$ el número de comentarios. (Madrigal Romero, 2015, p. 22)

Los filtros, el hashtag (\#), los likes, los comentarios y menciones, las notificaciones (@) y los videos fueron parte de los recursos que se utilizó en la Campaña y sus cuentas sedes como Aborto legal Mendoza (https://www.instagram.com/ abortolegalmza/) o la cuenta del Plenario de las Trabajadoras (https://www.instagram.com/plenariodetrabajadoras/), por nombrar dos colectivos que se suman en la lucha por la legalización de la IVE. 
Figura 13: publicación de Instagram de abortolegalmza (12/2/2020) Convocatoria 19F.

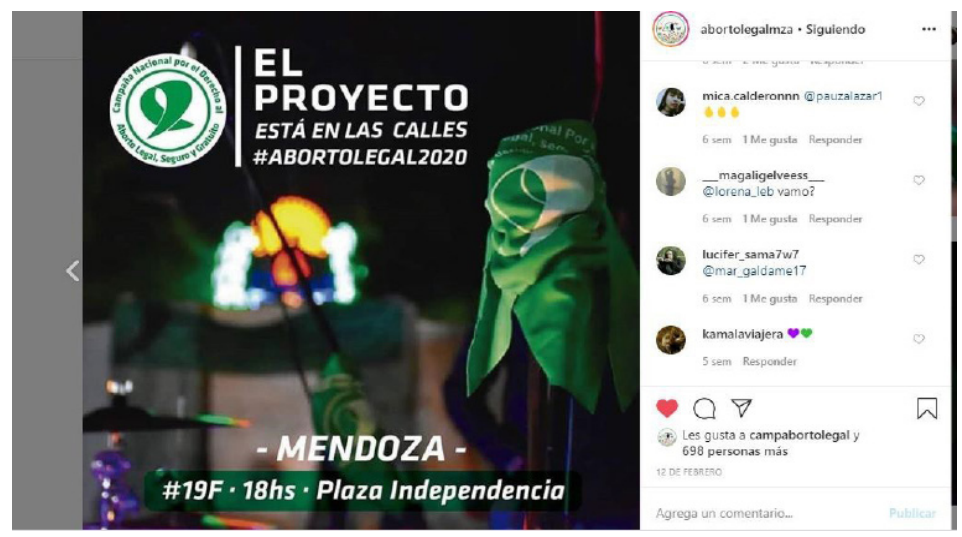

Fuente: Recuperado de: https://www.instagram.com/ abortolegalmza/?hl=es-la

En primer plano el pañuelo verde y en segundo plano el escudo de la Plaza Independencia (corazón de la ciudad de Mendoza y de las protestas y actos), el tema (El Proyecto) y la presencia del color verde de la Campaña. Los comentarios (entre las usuarias) no sólo eran de interacción con la cuenta de Instagram sino entre ellas, likes (698) y emojis (corazones con los colores emblemáticos del feminismo: violeta y verde). En la fecha de la publicación (12/02/2020) a 668 personas les había gustado la publicación.

La militancia virtual aún permitía mantener los ejes de la lucha del movimiento feminista en Argentina por los feminicidios, como fue en este caso durante la cuarentena (aislamiento social obligatorio) por el COVID-19: convocatoria al ruidazo por los feminicidios ocurridos en los primeros 10 días de cuarentena: el ruidazo federal era una convocatoria a una acción colectiva, aunque ésta fuera un acto individual porque se entendía la ASPO como medida de fuerza mayor. La tipografía y el fondo de los flyers en la combinación de violeta y verde. 
Figura 14: publicación de la página de inicio en la cuenta de Instagram de abortolegalmza Convocatoria Ruidazo.

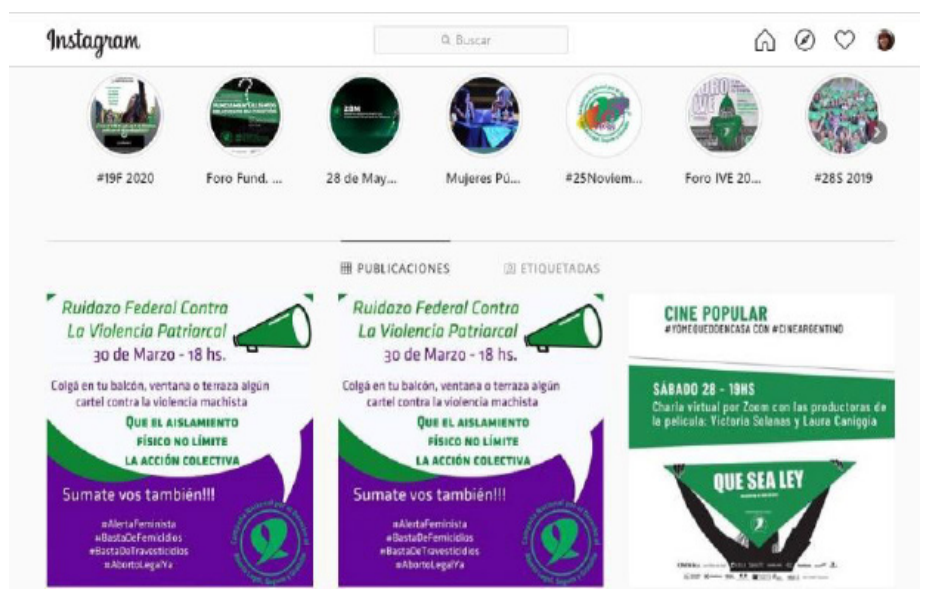

Fuente: Recuperado de: https://www.instagram.com/ abortolegalmza/?hl=es-la

Además de las aplicaciones extras o los recursos como los mencionados, la autora con la que estamos desarrollando este apartado de las características de Instagram, Madrigal Romero destaca el sistema de recompensa (likes y comentarios por la publicación de las fotos), la simpleza de su uso, la accesibilidad y el engagement (compromiso) que se fortalece en el tema y la audiencia (en nuestro caso la Campaña y sus militantes y potenciales usuarios a los que llegaría). Ese compromiso será, por ejemplo, parte del éxito del filtro del pañuelo sumado a la presencia de una influencer como se ha mencionado.

Madrigal Romero (2015, p. 30) recupera en su artículo las características de Instagram señaladas por Harbour (2012) y que sintetizan las respuestas al éxito de la red social. Estas ventajas que permite el uso de Instagram como red social, sus usuarios/as, la posibilidad del compromiso y el uso de filtros y de mensajes construidos visualmente fueron los aspectos que observó y reconoció la Campaña Nacional por el Aborto legal (CNAL) considerando la masa de adolescentes que se habían sumado al movimiento, sus hábitos sociales y prácticas culturales de comunicación.

La marea verde potencial usuaria de Instagram por su corte etario entre los 14 y 25 años, los millenialls y centennials que engrosaron y le dieron un recambio generacional a la Campaña, también forzó a pensar en otros espacios de militancia como el de las redes. Facebook, WhatsApp e Instagram serán los nuevos territorios. 
Los aspectos que se consideran exitosos de Instagram según Harbour son:

1. Es social, contamos nuestra cotidianidad y nuestro entorno

2. Es fácil de usar y podés usar tus fotos con los filtros y recursos de edición además de agregar comentarios, localización, etiquetas

3. Es instantáneo: es rápido y te ofrece la recompensa de la publicación y del reconocimiento de tus seguidores.

4. Es creativo, podés usar filtros e intervenir las imágenes: Instagram transforma la realidad.

5. Instagram es gratuito (Madrigal Romero: 30 )

Esto podría explicar la expansión de la lucha feminista que se dio en el terreno digital en Argentina y su uso por parte de la Campaña (CNAL) entre 2018 y 2019, e incluso en la actualidad: permitió que los followers de la Campaña pudieran socializar, informarse e identificarse como tales, se subieran las fotos y videos que registraban los actos en los que participaban.

En cuanto al potencial público, Instagram propuso frente al impacto de la presencia de la marea verde y la tendencia, un concurso de filtros que fuera usado por los y las seguidores/as de la Campaña como un fenómeno de viralización.

\section{Instagram y la imagen como práctica discursiva}

Al hablar del uso de las herramientas digitales en la experiencia del activismo, Instagram sensible al contexto de participación por el debate de legalización y despenalización del abortoy a la edad de quienes se suman a estas convocatorias definida como la marea verde abrió a sus usuarios en el 2018 la posibilidad de reunir lo visual como símbolo y como emblema de una generación, tanto por lo que significaba como por la modalidad de diseño, producción, discurso y circulación (los estratos a los que refiere la Semiótica Visual Multimodal).

Por otra parte, en consonancia con la Campaña (\#CampAbortoLegal) Instagram organizó en el 2018 (Insausti, 2019) una convocatoria para que los usuarios participaran creando filtros y los subieran a sus "stories" mediante un software libre con la posibilidad de que pudiera ser accesible al público. La idea base con la que trabajaron los ganadores (Josefina Mateo y Ezequiel Scarpini) es que el uso del pañuelo en su formato físico no siempre encontraba un contexto 
amigable para este tipo de exposiciones y manifestaciones políticas sobre la IVE. Lo analógico con su fuerte carga simbólica da paso al filtro con su uso colectivo y a la vez individual en los perfiles de las cuentas de Instagram.

La convocatoria activó la participación de sus usuarios (en términos etarios jóvenes y competentes digitales), y con ello, sumarse virtualmente a la Campaña y seleccionar la imagen a la que agregar el filtroy, por otra parte, permitió, participar de manera simultánea y ser parte de una red más grande. Estas cualidades que giran en torno a la accesibilidad, ser miembro de una comunidad, participar y al mismo tiempo, identificar a quien seguir o ser seguidos por la exposición en las redes frente a la IVE. La particularidad que genera el engagement en Instagram, la potencia de las imágenes, la asociación a otras redes (Facebook), el uso de filtros, la recompensa de los likes en las publicaciones y la selección que como audiencia realizamos, la hacen no sólo una plataforma amigable sino de real llegada a diferentes sectores sociales.

La convocatoria de Instagram del 2018 que consagró a Mateo y Scarpini como ganadores también hizo pública la trayectoria de los jóvenes. Insausti (2019) recalca que "desarrollaron un filtro por el aborto legal, seguro y gratuito que se multiplicó orgánicamente en Latinoamérica y el mundo." El uso del filtro (la potencia significativa y material de la aplicación en Instagram) con la forma simbólica del pañuelo y el color verde se crearon específicamente no sólo para que se identificaran quienes adherían a la lucha de la Campaña, más allá de cualquier posicionamiento político, sino, incluso estaba destinado a usuarios/as que en el escenario de lo físico se sentían inhibidos, atacados o censurados si eran descubiertos sus pañuelos de algodón entre sus pertenencias o si los usaban. Sin dudas, Mateo y Scarpini, estuvieron atentos a lo que significaba usar el pañuelo verde en una escuela u oficina, o en la misma vía pública, tomaron la convocatoria de Instagram y decidieron realizar un aporte que fue utilizado por miles de usuarios/as. El filtro, su uso y su carga simbólica, es lo visual como discurso ya que quienes descargaban y aplicaban el filtro en sus fotos de perfil no sólo se identificaban públicamente, sino que además disputaban el sentido de ser parte de algo colectivo y más grande.

Al profundizar sobre el uso de la plataforma y las herramientas digitales como otro territorio de expansión de lo simbólico del color, el pañuelo y sus aportes en la lucha 
del movimiento feminista, la llegada del filtro se realizó de manera gradual pero vinculado al storytelling del mismo pañuelo. La presencia de influencers o de figuras que aportan miles de seguidores permitió la viralización de su uso. Es decir, que las posibilidades tecnológicas de Instagram, los factores como accesibilidad y expansión se suman a un proceso cultural y social particular del movimiento feminista: sus usuarios y la participación activa de los mismos.

Josefina Mateo define su generación y cómo se suma a la lucha por los derechos como la que se anima a decir y a romper los mandatos:

Estamos viviendo el despertar de una generación que ya no se calla, que habla y exige sus derechos en un contexto en donde, por muchas generaciones, el mandato fue callar"'” (Josefina Insausti: 2019)

Las potencialidades de Instagram se desarrollaron en un contexto en el que los usuarios buscaban y eran estimulados a participar, más allá del simbolismo del color verde y de la forma del pañuelo expandido en Argentina, la idea de la aplicación planteó como explican los creadores (Scarpino y Mateo) un "carrousel de filtros" que permitiera el diálogo entre lo global de Instagram y lo local o esa mirada particular o insight en otros países latinoamericanos. El fenómeno de la viralización rompió con lo local en relación al color verde, el pañuelo, mantuvo el eje semántico simbólico con la lucha de los derechos sexuales y reproductivos, y al mismo habilitó a darle esa tonalidad que implica sumarse a la Campaña en tono latinoamericano, diverso y territorial al mismo tiempo.

El uso del filtro nace como espacio de manifestación, un uso militante en lo virtual:

El pañuelo verde en Instagram les da a las personas otro espacio menos riesgoso para expresarse. Es "un lugar más seguro y que es tuyo, en donde vos compartís quién sos en lo que creés" (....) "Quizás hay mujeres que no se animan a salir a la calle con el pañuelo porque si lo hacen son agredidas. Hay personas que no pueden iniciar la conversación sobre el tema en la oficina porque son censuradas." (Josefina Mateo:2019)

Instagram fue, de esta manera, aparentemente reutilizada como red social y espacio de reconocimiento, caminar por la ciudad y llevar el pañuelo en la mochila tenía su equivalente en la foto de perfil. La accesibilidad, la potencia de 
viralizar, la facilidad y la exteriorización sin efectos adversos de una posición política frente a la IVE fueron las ventajas que ofreció el uso de esta red social.

Figuras 15 y 16: Las Instrucciones para utilizar los filtros se encuentran en la misma red de Instagram.
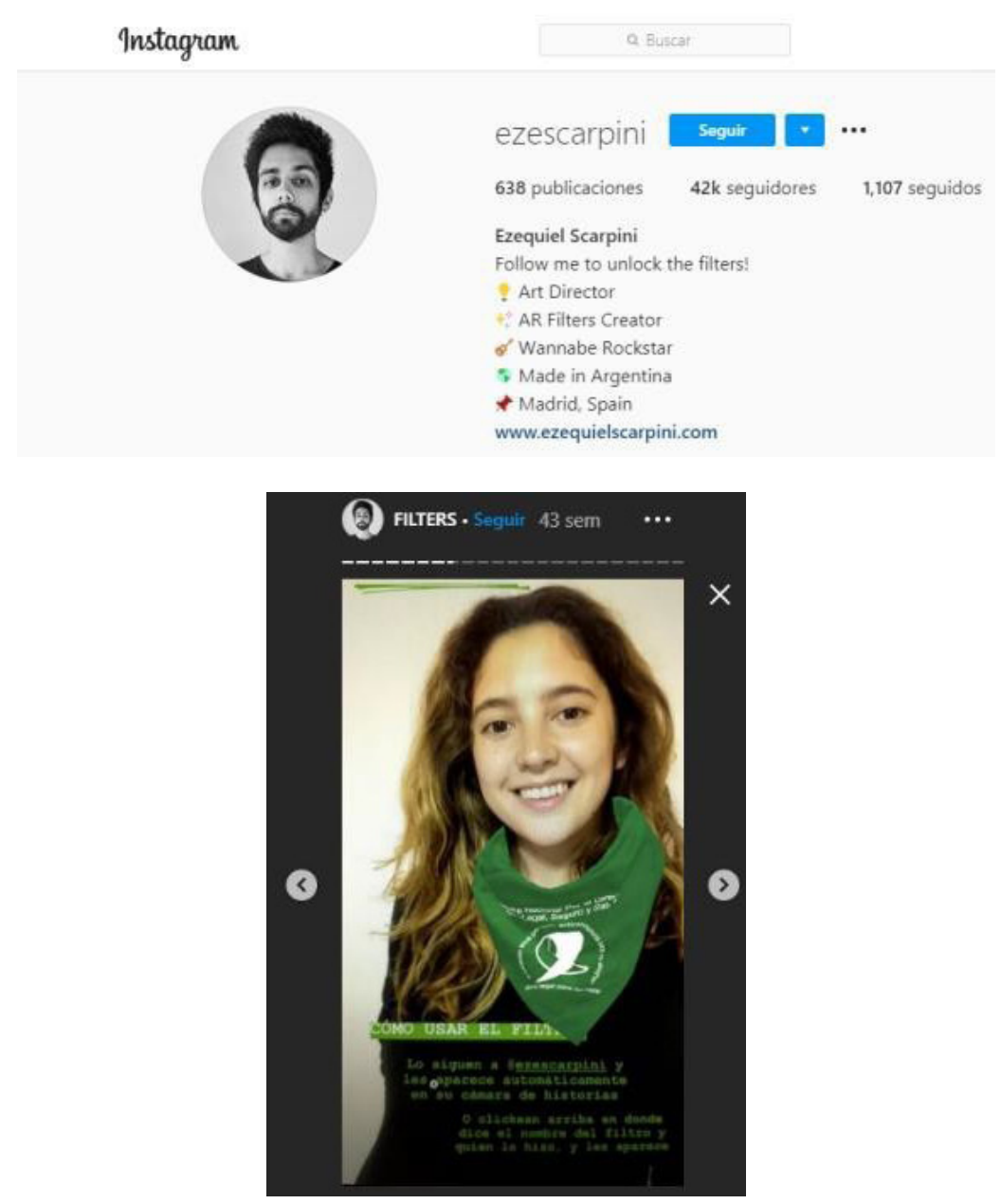

Fuente: Recuperadode:https://www.instagram.com/accounts/ login/ en la cuenta de su creador https://www.instagram.com/ ezescarpini/

\section{Lo visual: disrupción y ruptura}

Como se señalado anteriormente, a esa interpretación casi neutra del verde que marca Heller, en Argentina, se incorporó el llamado verde "aborto" que formará parte de una gramática visual (su tonalidad, carga simbólica y uso) que se sumará a la lucha de las mujeres, además de un sinnúmero de símbolos y expresiones que manifestarán los sucesivos reclamos por la igualdad de derechos a lo largo de la historia 
del feminismo.

Durante el 2018 con los debates en el Congreso para la despenalización y legalización del aborto: la marea verde cruzará los distintos grupos etarios y cerrará el círculo que las hubo hermanado desde el 2003 en el XVIII Encuentro Nacional de Mujeres en Rosario el pañuelo verde de las nietas con el blanco y símbolo de lucha por los derechos humanos de las Madres de Plaza de Mayo.

Un color vacío en la cadena de significados políticos, el consenso entre las agrupaciones y colectivos feministas que empujaban los proyectos de ley sobre el aborto y una casualidad dieron inicio al pañuelo verde que crece en miles y a pasos agigantados como símbolo y valla para defender los derechos de las mujeres a decidir sobre la maternidad. Junto con la hermandad que generará el color prendido en mochilas, carteras o abrazando muñecas o cuellos, también será el objeto que comenzará a desatar ataques desde los sectores antagónicos a los grupos que promueven la interrupción voluntaria del embarazo. Este lazo visible de quienes se sienten protegidas por el color del pañuelo, traerá en su reverso simbólico el blanco de las agresiones denunciadas por Amnistía Internacional en su Informe de diciembre del 2018 en el que se registran desde ataques verbales hasta físicos a quienes son sorprendidos portando el mítico pañuelo verde en algunas ciudades de Argentina.

Los colores, recargados de un significado ideológico, más la referencia a los pañuelos de Plaza de Mayo, no sólo llenarán los espacios físicos de las plazas y las calles; se sumarán a la cotidianeidad y a los espacios urbanos en murales y pintadas que dejan las huellas del paso de la marea verde. Llenarán los espacios digitales de las plataformas como Youtube, las imágenes de acceso público en buscadores como Google, serán posteados, prestados, customizados y compartidos a través de redes sociales como Instagram, Twitter o WhatsApp. En las marchas y actos del movimiento feminista en Argentina, las mujeres llevarán sus pañuelos, sus compañeros los portarán y subirán a las redes y plataformas las imágenes de la marea verde. A veces el color, a veces la silueta del pañuelo, a veces una furtiva intervención, a veces, solo a veces una foto mostrando el pañuelo o llevándolo a algún acto oficial.

Los espacios institucionales comenzaron a ser incorporados a los pañuelos verdes y viceversa; los colores que a principios del siglo XXI se asomaban en los debates de los 
colectivos y agrupaciones feministas rompieron las propias vallas de los grupos y se expandieron a cientos de miles. Los pañuelos originales o los que se hacen caseramente se mueven sin distinción de marca de fábrica; sufren el ingreso al mercado y tienen precios variados entre los que ofrecen las militantes o los vendedores ambulantes.

Figura 17: Foto 34 ENM (Encuentro Nacional de Mujeres) en La Plata: PDT. 13/10/2019

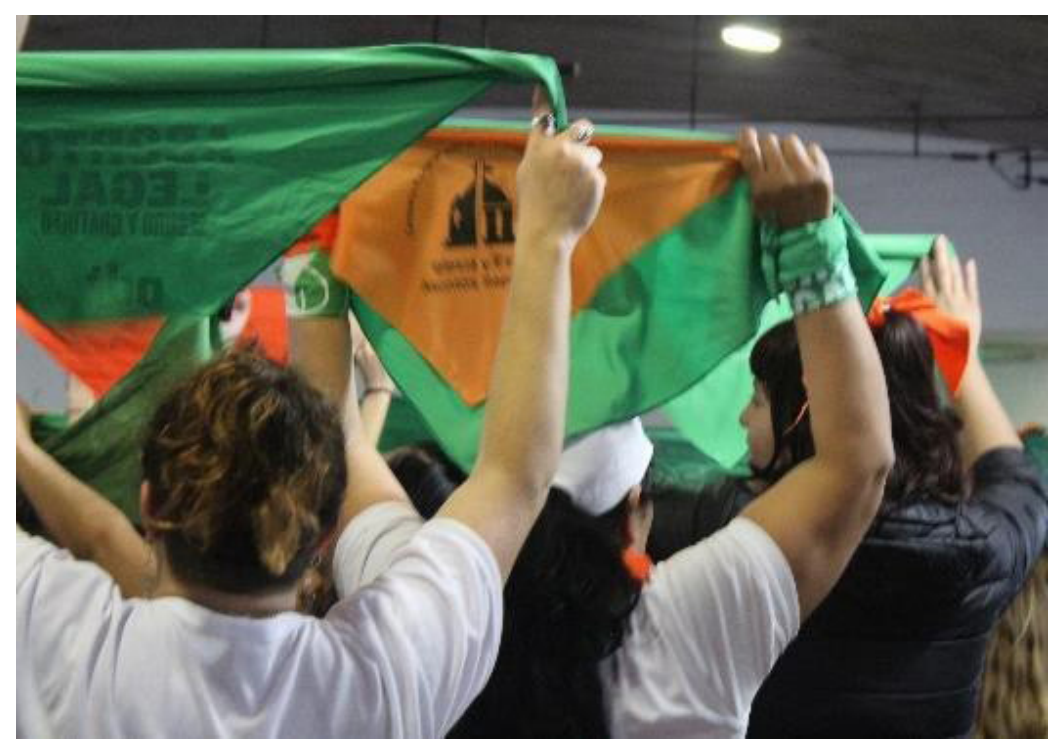

Fuente: Fotografía de Verónica Torres.

Figura 18: Foto: Verónica Torres. Foto Marcha \#8M en Mendoza. Ciudad de Mendoza. 8/3/2019

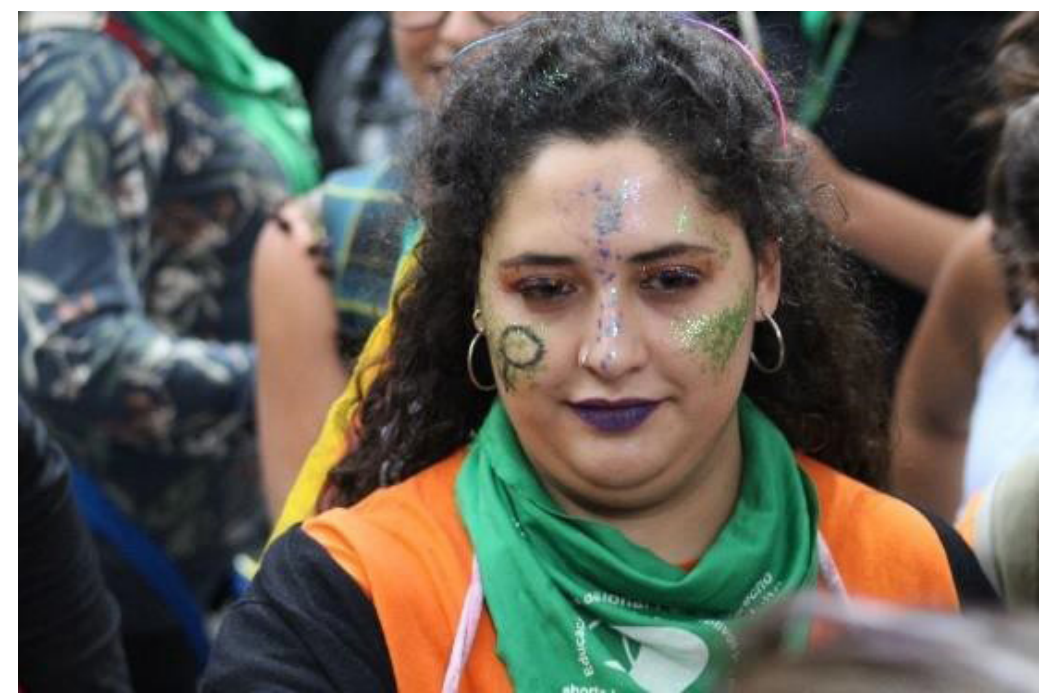

Fuente: Fotografía de Verónica Torres. 
En la etapa preliminar y en el avance de la cultura digital, coparon el espacio de la prensa digital, nota de portada, crónica o nota de color, el significado del verde, el porqué del color elegido y la historia del pañuelo fueron parte de las noticias entre los meses de junio y agosto de 2018 en el escenario del debate en el congreso nacional argentino.

Sobre el simbolismo de los colores en las acciones de la Campaña Nacional por el Aborto Legal, el diario La Nación (6/3/2018) se expedía al respecto al inicio del debate:

Miranda Gonzalez Martin, antropóloga e integrante de la campaña, contó que era un color que estaba vacante. "El violeta es el color del feminismo y está muy extendido; el naranja lo suele usar la Iglesia; el rojo los partidos políticos de izquierda y el azul lo ha usado históricamente el justicialismo. En ese espectro de colores visibles, el verde era un color que no estaba usado".

Figura 19: Color, pañuelo y \#8M. Entrevista a Soledad Sosa (PDT-Mendoza:8/3/2019) Autora: Verónica Torres. https://youtu. be/o_uW40JBKXY

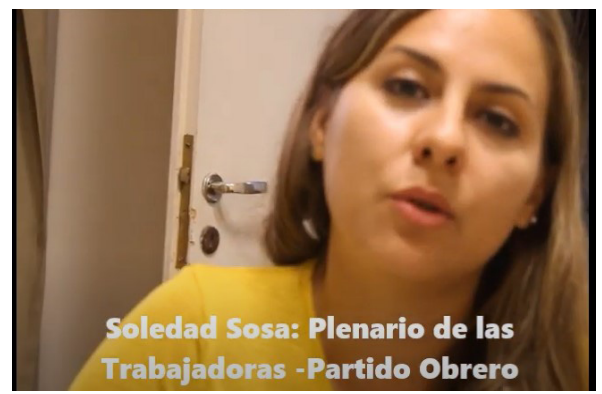

En la voz de la diputada nacional Soledad Sosa y militante del Plenario de Trabajadoras de Mendoza (8/3/2019) "el pañuelo verde es un símbolo de libertad en nuestro país que se suma a otros. Son todos pañuelos que representan las luchas históricas."

\section{Lo visual en clave multimodal: imagen, color, fotografía}

Como señala Soledad Sosa (2019) miembro del PDT, los alcances tecnológicos que implicaron el uso de celulares y las plataformas de acceso libre como las que alojan a las redes sociales (Facebook, wasap o Instagram) permitieron en principio abrir intersticios dentro el campo comunicacional 
que los procesos de concentración y convergencia al mismo tiempo cerraban a los grupos, comunidades y sectores minoritarios en el espectro político; en segundo lugar, la circulación de documentos dentro de los miembros de estos sectores y, finalmente, la expansión del radio de acción en la práctica militante por los derechos de la mujer vinculado, éste último, a la defensa de los reclamos por la despenalización y legalización del aborto.

Las redes sociales serán también el campo de la marea verde, quienes por sus características generacionales éstas les son familiares como el uso de objetos simbólicos como el pañuelo verde o simplemente el color verde (Luciana Peker (2019) La revolución de las hijas).

En un universo macro, la Campaña dialogará con estos grupos a través de sus cuentas de Instagram y abrirá las convocatorias a todas las agrupaciones, colectivos y diferentes sectores independientes bajo el simbólico uso de los colores: el lila (color histórico del Feminismo) y el verde. (Sandra Arbat: 2018)9.

Como se ha mencionado anteriormente, la Semiótica Multimodal (ACDMultimodal/ Kress y van Leuween) propone abordar los discursos en los que se combinan diferentes sistemas de signos (modos) y los mecanismos que se emplean para su producción y comprensión. Por esta razón, el proceso implica la descripción e interpretación de los recursos semióticos, de los modos empleados, del medio en el que se difunde el discurso, y de las prácticas comunicativas para dar cuenta de la manera cómo, a partir de un discurso, se construyen saberes colectivos. En este tipo de análisis se distinguen cuatro estratos analíticos, que son: discurso, diseño, producción y distribución.

Gunther Kress, Theo van Leuween y Regina LeiteGarcía (1997; 2000) plantean que se hace necesario tomar el enfoque multimodal para comprender todos los modos de representación que entran en juego en el texto. El enfoque multimodal implica que un texto, por ejemplo, no tiene una sola forma de representación y comunicación; y se parte del presupuesto en el que un modo específico (visual, gestual, sonoro, por ejemplo) tiene potencialidad de significación y limitaciones que deben tenerse en cuenta, ya que toda práctica semiótica social implica formas de significación que se producen dentro de una actividad social enmarcada en el campo de la política y también en un campo de disputas de

\footnotetext{
9 Por qué el color violeta es el verdadero símbolo de la marcha feminista del Día de la Mujer https://www.lavanguardia. com/de-moda/
} 
poder.

Designamos a esta práctica semiótica social para llamar la atención sobre todas las formas de significación como actividad social enmarcada en el campo de la política, de las estructuras de poder $y$, por lo tanto, sometida a las disputas que surgen debido a los intereses de los que producen textos." (Kress, van Leuween y Leite-García, 2000, p.375)

Los discursos se forman en el cruce de diferentes modos y excede lo meramente lingüístico; por ejemplo, publicidades, videos, artículos en los que texto e imagen son componentes que forman una experiencia de interpretación en la que un lenguaje noes predominante sobreotro; sia ello, consideramos el uso de las tecnologías y nuestras experiencias en las redes sociales, plataformas y aplicaciones, se complejiza aún más pensar en el discurso exclusivamente asociado a lo verbal.

En estas dimensiones se deben interpretar lo relacional, lo social y lo organizacional; la publicación de Instagram de la cuenta del PDT, como muestra la imagen recarga el predominio de la modalidad visual (la fotografía) y el texto no funciona como complemento sino como una producción de modalidad verbal (lingüística) de autoría colectiva, cuyos enlaces permiten la circulación con los \# que asocian a las agrupaciones, usuarios/as independientes y colectivos con la cuenta institucionalizada como @abortolegalmza y, en consonancia, con \#CampAbortoLegal.

Figura 20: Publicación de Instagram: PDT (19/11/2020)

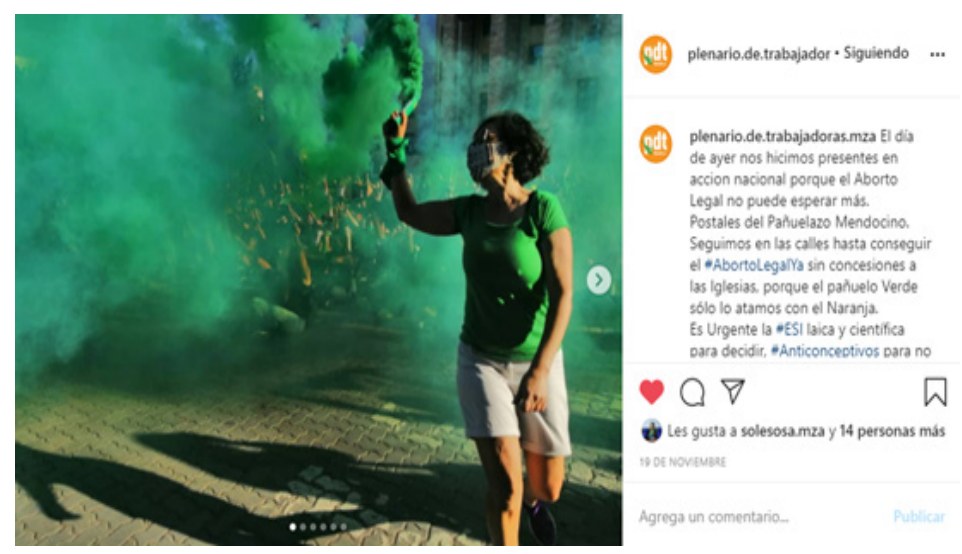

Fuente://www.instagram.com/plenario.de.trabajadoras. mza/?hl=es-la 
En cuanto al uso de los colores con su carga simbólica y las potencialidades de Instagram, se puede apreciar en el siguiente ejemplo la distribución espacial en la composición de la imagen y el peso de la atención en la misma:

Figura 21: Cuenta de abortolegalmza: convocatoria de la Campaña a las usuarias de la cuenta de Instagram a "militar" virtualmente la presión por un proyecto de ley de IVE que estará en los anuncios del discurso inaugural del presidente Alberto Fernández del 1ero de marzo de 2020. Convocatoria al Ruidazo (1/3/2020).

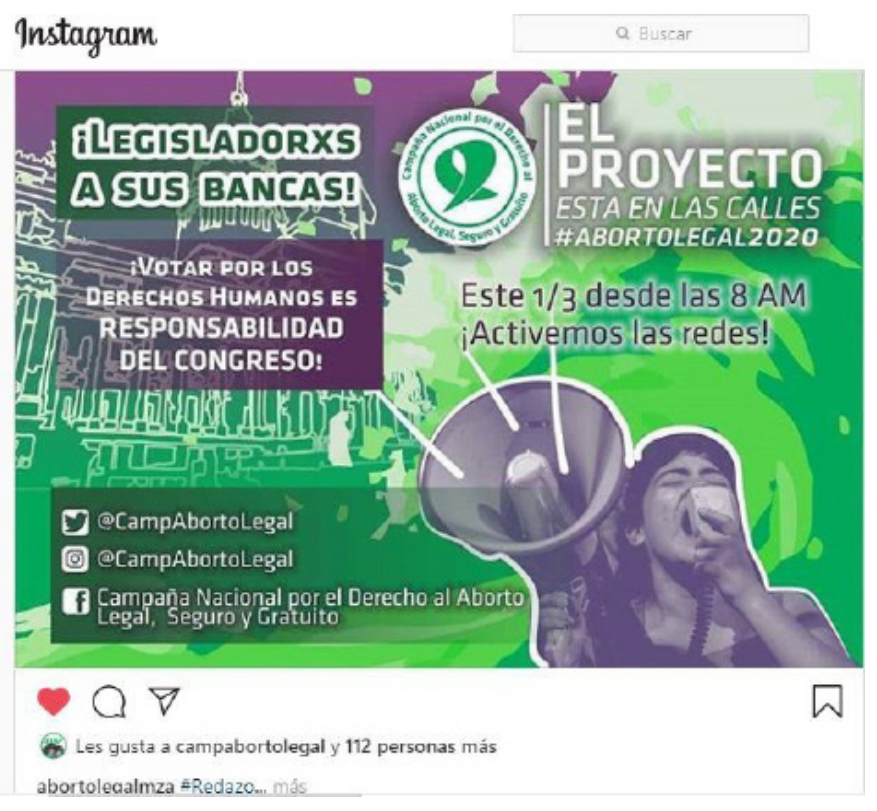

Fuente: Recueperado de: https://www.instagram.com/ abortolegalmza/?hl=es-la

El fondo con los colores simbólicos: el histórico lila del movimiento feminista y el verde de la Campaña enmarcan las imágenes con las que se armó el relato: el Congreso, la convocatoria y las líneas de la marea verde en movimiento dando la percepción de movimiento. En la parte central del flyer (en la relación de los tercios) en términos de composición de la imagen, el logo de la Campaña sostiene el carácter institucional. El listado de las cuentas en las redes sociales con la función de contacto y la convocatoria " $a$ activar las redes" posibilitan la visualización y el compromiso de sus seguidoras: interacción, accesibilidad, compromiso características de la militancia web 2.0.

Los pañuelos llenan el terreno de lo digital y el activismo virtual será otro campo discursivo en el que las estrategias 
estarán en función no sólo de mantener el reclamo sino de motorizar variadas formas de participación ciudadana.

Por otrolado, además delverde aborto y el violeta, se suma otro color al simbolismo cromático en la lucha del feminismo en Argentina: el naranja. El color naranja, estridente y nuevo (Heller:2008) será la más reciente incorporación en el campo visual ideológico con la demanda de separación iglesia/ estado luego de la derrota en el Congreso en la votación de agosto/2018.

Para retomar la lucha por la legalización y despenalización voluntaria del embarazo y la aplicación efectiva de la ESI, luego del embate de las instituciones clericales y del heterogéneo universo religioso, la batalla por la IVE se reinició con los reclamos desde las bases por una ruptura institucional y efectivo. Para poder retomar el debate sobre la IVE, antes se requiere cortar con los lazos institucionales entre el estado y la iglesia. Desde el marco del ACD, el discurso eclesiástico interviene desde una estructura argumentativa basada en los topoi de historia, cultura y tradición (sobre la presencia institucional y política del clero en la vida oficial y política del estado argentino) y los topoi de humanitarismo, legalidad y derechos (Wodak y Meyers, 2001).

El pañuelo naranja unido al verde completará la demanda: aborto legal, seguro y gratuito y separación de la iglesia del estado, como señala Romina Del Plá (diputada nacional: PO-FIT, 13/06/2018) "Y esto es mucho de lo que estamos discutiendo acá, porque vemos como esta irrupción de la ola verde tiene que ver con romper ese tutelaje de la Iglesia y del Estado."

Figura 22: Foto Pañuelazo \#8M 2020, Plaza Independencia: PDT-Mendoza.

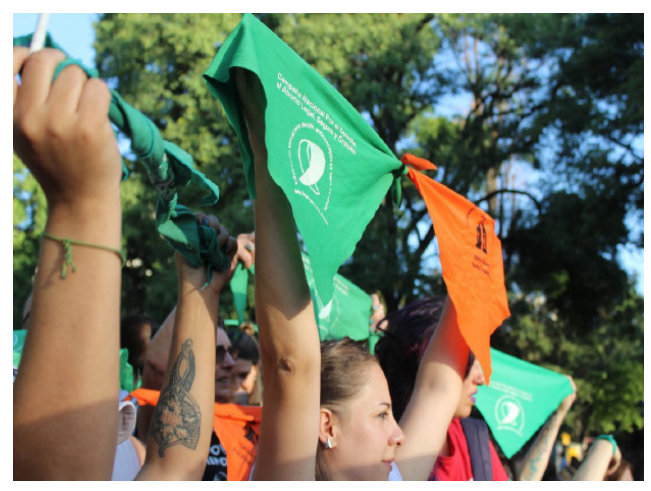

Fuente: Recuperado de: https://www.facebook.com/ observatoriodemediosdelodiscursivoalosocial 


\section{En Instagram todos/as somos fotógrafos: a modo de conclusión}

Figura 23: Foto: Soledad Tolaba (militante del PDT-Mendoza) que circula en los grupos de WhatsApp antes de ser subida a la cuenta de Instagram. Casa de Gobierno, Ciudad de Mendoza. 18/11/2020.

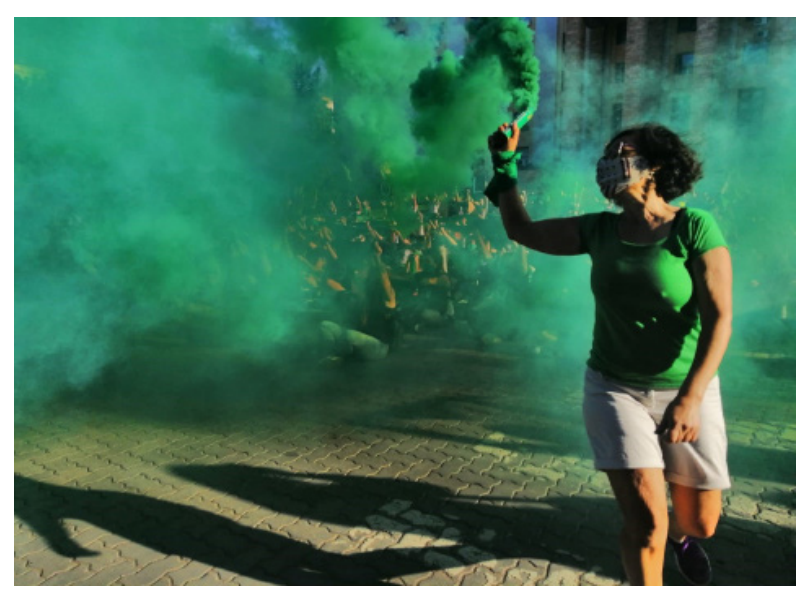

Figura 24: la foto ya como parte de la publicación de Instagram, el texto señala el evento, el posicionamiento del colectivo participante, el evento de registro fotográfico y los ejes de la campaña articulada: \#AbortoLegalYa y \#ESI reforzadas en la explicación del uso conjunto de los pañuelos verde y naranja. Publicación del 19/11/2020.

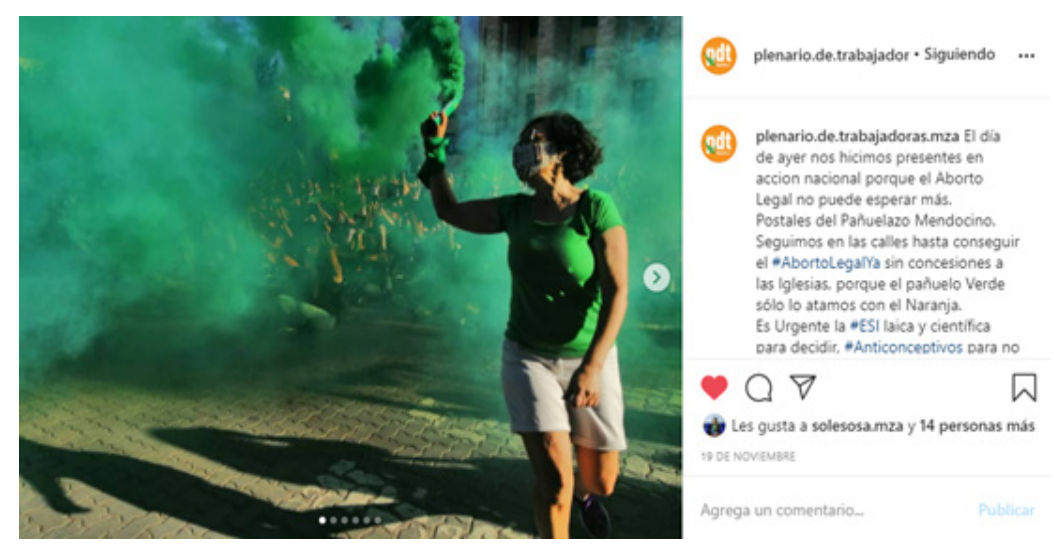

Fuente: Recuperado de: https://www.instagram.com/plenario. de.trabajadoras.mza/?hl=es-la

Instagram es la red de lo visual, registra en el espacio de lo virtual lo que ha ocurrido en el espacio de lo físico, analógico, ese "estar allí" y ser testigo y compartir para que otros formen parte de este relato. Una militante del PDT- 
Mendoza, el 18 de noviembre de 2020 registra con la cámara del celular uno de los rituales del Pañuelazo en la explanada de la Casa de Gobierno en Mendoza. La foto se comparte en los grupos de WhatsApp, y con la protagonista retratada. Se sube a Facebook y se vuelve a hacer circular, hasta que finalmente, la cuenta oficial de Instagram del PDT, la emplea como imagen ícono de las llamadas "Postales del Pañuelazo Mendocino".

La autora de la foto no era una/o de las/os fotógrafas/ os profesionales que allí se habían reunido para registrar el acto superada la etapa de cuarentena (DNU 297/20), es una de las militantes que se ha acercado a participar. En el momento en que las organizadoras de la actividad deciden el uso de las bengalas de humo verde se activa la tarea del registro fotográfico; como en otras oportunidades, es la imagen captada por un/a usuario/a con un dispositivo móvil.

Sobre la relación foto-dispositivo y el registro del evento, señala Eliana Méndez (militante del PDT-Mendoza) "Esa foto la tomó Soledad Tolaba; yo estaba con la bandera y le pasé mi celu para que saque fotos. Ni ella sabe cómo tomó ese momento, estaba asombrada." (Entrevista a militantes del PDT: 3/12/2020)

Para detallar esta relación entre usuarios que están en actividad en las redes sociales, tomaremos algunos conceptos desarrollados por Natalia Aruguete y Ernesto Calvo (2020) sobre los comportamientos de las redes sociales en sociedades polarizadas que se mueven en burbujas; la investigación desde el marco teórico cognitivo trata de buscar respuestas a los procesos de retroalimentación entre medios de comunicación-redes sociales, en particular: Twitter; para este artículo, es posible que puedan explicar estas relaciones en Instagram.

Si tomamos el ejemplo de la cuenta del PDT-Mendoza y la oficial de @AbortoLegal, esta práctica discursiva y social que podríamos describir como "consonancias", y en particular, en lo relacionado con la Campaña Nacional por la Legalización del Aborto, en lasredes sociales se deben a que ciertos temas y eventos no están polarizados. Esta no polarización se da en las formas y permite construir narrativas con mayor presencia de usuarios/as al mismo tiempo que disminuye la presencia político-partidaria de algún referente específico al que se sigue en las redes.

La mareaverde, personificada en cuentas independientes 
o de colectivos asumió su rol como enunciador/a legitimado/a por su propia trayectoria de institucionalización. Este cambio, señalan Aruguete y Calvo (124:2020) fue posible en el nivel del tema más que en la forma de la interacción de los/ las usuarios/as, en términos generales, porque existió una topología de temas en las redes que activan o no a usuarios y que en diferentes dimensiones, desde lo ideológico a lo sociocultural permitieron establecer que en una determinada dimensión se pudieron encontrar comunidades aisladas en burbujas que no compartieron información y por ello, existía polarización, y en otras, no y se abrían las vías, es decir, no se redujo ni se aisló. A ese movimiento en las dimensiones, los autores lo definen como rotación topológica ya que los/las usuarios/as focalizan temas en diferentes dimensiones.

Al mismo tiempo, en esas rotaciones topológicas, determinados eventos quedan localizados en ejes dominantes que permiten que la polarización sea menor y por ende que sea una red densa; en esta categoría, Aruguete y Calvo ubican a \#AbortoLegal como una antirred.

La denominación de antirred se debe a que se logró con la instalación del debate, la organización de lo que los autores denominan "la red verde" y la forma de actuación de los y las usuarios/as que, incluso, en la órbita política oficial en el 2018 , existieran posicionamientos a favor y en contra, al igual que en la oposición.

definimos \#AbortoLegal como la antirred, en la medida en que el nivel de polarización fue más bajo, el diálogo político más extenso, el grado de jerarquía fue sustantivamente menor y el tono que caracterizó a los mensajes fue más pedagógico y menos "chicanero". Sin embargo, los usuarios que la integraron son los mismos que participan en comunidades polarizadas $y$ las conexiones entre ellos permanecieron relativamente inalteradas. \#AbortoLegal no es una antirred porque su topología y sus usuarios hayan sido diferentes; su singularidad reside en que rotó y quedó ubicada fuera del eje dominante gobierno-oposición. (Aruguete; Calvo: 130, p.2).

En correspondencia con el campo de la cultura digital y el complejo mecanismo en el que comunicación, legislación, normas, uso y restricciones en este universo, las redes sociales Instagram y WhatsApp (las aplicaciones adquiridas por Facebook) junto a la empresa marco conformaron un espacio de expansión y penetración en el modo de comunicarse 
e informarse para millones de usuarios conforme rasgos etarios, potencialidades de uso lo que ofrecen estas redes y la plataforma a la que estaban vinculadas.

Al mismo tiempo, al estar asociadas redes y plataforma y ser utilizadas a partir de la tecnología disponible en los dispositivos móviles (mucho más expandidos que otros dispositivos como la notebook, televisión o Tablet) y definir una manera cultural de construir relaciones entre los usuarios y de estos con los circuitos de circulación de información y de acceso a la misma se plantearon serios desafíos en cuanto a la relación entre difusión, expresión, privacidad, industria cultural y conocimiento.

Comomuestranlos resultadosdelainvestigación enenero de 2019 que realizó We are Social y Hootsuite, Instagram, no sólo registró el mayor incremento entre usuarios, sino que el rango de edad de estos oscila entre 18 y 25 años, un corte etario que diferencia a los que sobrevuelan con mayor permanencia en Facebook; y WhatsApp con un crecimiento de más de 1500 millones de usuarios activos. Instagram que nació como una red social para compartir fotografías y videos.

Los alcances del uso de \# hashtag y los cruces entre feminismo y tecnología han sido expuesto en el Manifiesto para cyborgs por Donna Haraway (1991). También se puede consultar acerca del alcance del uso de las redes sociales, en particular Instagram, como estrategia de activismo social en el trabajo de Victoria Alejandra Delgado Ulloa (2016) y Rafael Carrasco- Polaino et al (2018) que desarrollan la relación entre imagen y texto en las campañas de las ONG "Activismo y ONG: Relación entre imagen y «engagement» en Instagram.

Una muestra del activismo fue la cuenta de Instagram de @abortolegalmza: la caída de las paredes de lo íntimo/ familiar/doméstico coincide con la cada vez más masiva y fuerte lucha de las mujeres por sus derechos, y que, en estas comunidades que se arman y tejen en sus lazos como redes sociales, cuando las usuarias o usuarios pidieron información sobre modos de interrupción del embarazo, previo a la legalización de la IVE, fue, quizás, sin lugar a dudas, en cientos de casos, redes de contención que salvaron vidas.

La presencia de la agenda de la IVE en las redes sociales como Instagram posibilitaron un uso democrático de la voz, de esa voz que estuvo silenciada y oculta, que irrumpe como un grito que convoca a defender la vida y exigir el libre ejercicio de los derechos sexuales y reproductivos. 
Figura 25: Casa de Gobierno, Mendoza. La foto para las redes del PDT-Mendoza (18/11/2020).

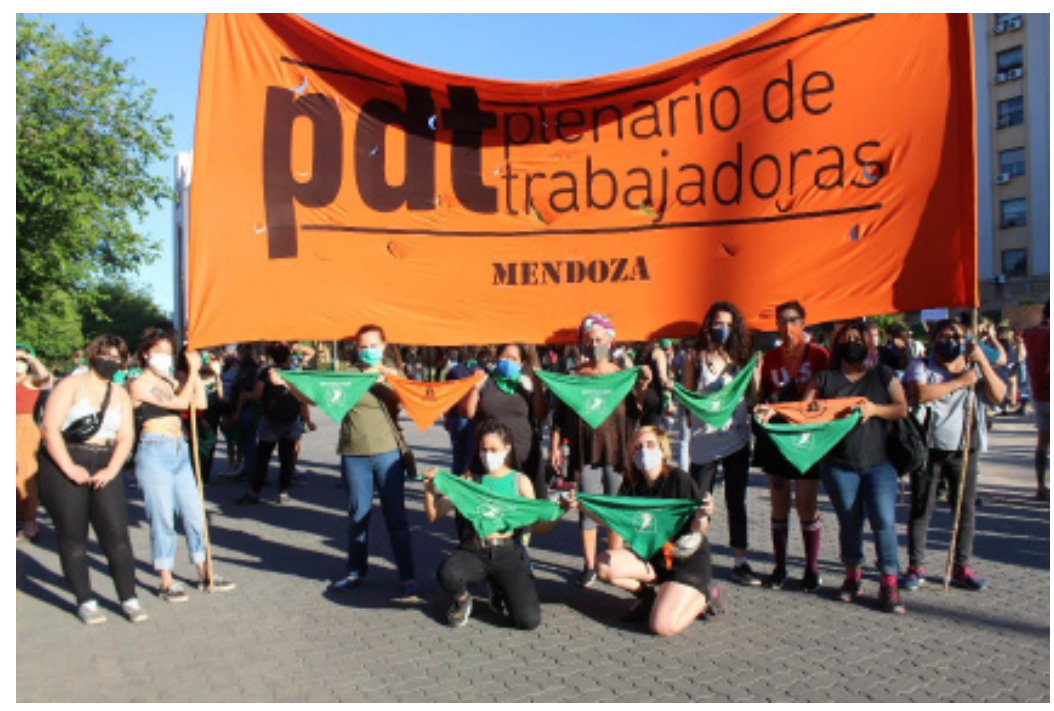

Fuente: Fotografía de Verónica Torres. Recuperado de: https:// www.facebook.com/observatoriodemediosdelodiscursivoalosocial

\section{Referencias bibliográficas}

Abuin Vences, Natalia (2009). Publicidad, roles sociales y discurso de género. En Universitat de Girona, Actes de Congènere: la representació de gènere a la publicitat del segle XXI.

Acosta, Marina (2018). Ciberactivismo feminista. La lucha de las mujeres por la despenalización del aborto en Argentina. En Sphera Publica, volumen 2, N¹8, pp.2-20. Consultado el 22/2/2021, en http://sphera.ucam.edu/ index.php/sphera-01/article/view/347.

Calvo, Ernesto y Aruguete, Natalia (2020). Fake news, trolls y otros encantos. Cómo funcionan (para bien y para mal) las redes sociales. Buenos Aires: Siglo veintiuno Editores.

Carrasco Polaino, Rafael; Cirujano, Ernesto y Cárdaba, Miguel Ángel (2018). Artivismo y ONG: Relación entre imagen y «engagement» en Instagram. En Comunicar, Revista Cientifica de Educomunicación, volumen XXVI, $\mathrm{N}^{\circ}$ 57. Recuperado el 5/12/2020, de https://www.readcube. com/articles/10.3916/c57-2018-03

Haraway, Donna (1991). Manifiesto para cyborgs: ciencia, tecnología y feminismo socialista a finales del siglo XX. En Haraway, D., Ciencia, cyborgs y mujeres. La reinvención de la naturaleza (pp.251-312). Madrid: Cátedra. 
Delgado Ulloa, Victoria (2016). Evaluación de la Incidencia de las redes sociales en el activismo digital y empoderamiento ciudadano.Tesisdelicenciatura.UniversidadCasaGrande, Guayaquil. Recuperado el 5/12/2020, de http://dspace. casagrande.edu.ec:8080/handle/ucasagrande/631

We are Social y Hootsuite (2019). Digital 2019 Global Gigital Overview (January 2019). Recuperado de: https://www. slideshare.net/DataReportal/digital-2019-global-digitaloverview-january-2019-vo1 22/2/2021

El cambio en la política de privacidad de Instagram irrita a los usuarios (2012, diciembre 18). La vanguardia. Recuperado el 5/12/2020, de https:/www.lavanguardia. com/internet/20121218/54358093776/el-cambio-enla-politica- de-privacidad-de-instagram-irrita-a-losusuarios.html

García Nieto, José (2019, agosto 23). Los 3 mejores filtros de Instagram para tus fotos. Aplicaciones Android. Recuperado el 5/12/2020, de https://andro4all.com/2017/03/mejoresfiltros-instagram-2017

Heller, Eva (2008). Psicología del color, cómo actúan los colores en los sentimientos y razón. España: Gustavo Gili.

InSAUSTI, Josefina (2019, septiembre 14). Dos alumnos crearon un filtro de pañuelo verde para Instagram. Miami Ad School Buenos Aires. Recuperado el 5/2/2021, de https:// www.miamiadschool.com.ar/blog/usar-redes-socialescausa-social- panuelo-verde/

InFORME We Are Social (2020). Recuperado el 22/2/2021, de https:/wearesocial.com/blog/2020/o1/digital-2020-3-8billion-people-use-social-media

Informe We Are Social (2021). Recuperado el 22/2/2021, de https:/wearesocial.com/es/blog/2021/o1/digital-report2021-el-informe-sobre-las-tendencias-digitales-redessociales-y-mobile

Kress, Gunther; Leite-García, Regina y Van Leuween, Theo (2000). Semiótica discursiva. En Van Dijk, Teun (comp.), En El discurso como estructura y proceso. Estudios sobre el discurso I: Una introducción multidisciplinaria (págs. 373416). Barcelona: Gedisa.

Laudano, Claudia (2019). Movilizaciones \#niunamenos y \#vivasnosqueremos en argentina. entre el activismo digitaly\#elfeminismolohizo. En Natansohn, G.y Rovetto, F. (orgs), Internet e feminismos: olhares sobre violências sexistas desde a América Latina (págs. 149-173). EDUFBA. 
Consultado en http://www.memoria.fahce.unlp.edu.ar/ libros/pm.3711/pm.3711.pdf Recuperado 22/2/2021

MejíA, Juan Carlos (2020, febrero 26). Estadísticas de redes sociales 2020: usuarios de Facebook, Instagram, Youtube, Linkedin, Twitter, Tiktok y otros. Juan Carlos Mejía Llano. Recuperado el 5/12/2020, de https://www.juancmejia. $\mathrm{com} / \mathrm{marketing-digital/estadisticas-de-redes-sociales-}$ usuarios-de- facebook-instagram-linkedin-twitterwhatsapp-y-otros-infografia/

Muzi, Carolina (2018). La historia del pañuelo verde: cómo surgió el emblema del nuevo feminismo en Argentina. Infobae. Recuperado el 5/12/2020, de https://www. infobae.com/cultura/2018/08/05/la-historia-delpanuelo-verde-como-surgio-el-emblema-del-nuevofeminismo-en-argentina/

NuÑEZ, Rodrigo (2019, 29 de mayo). ¿Lo usaste en stories? Un filtro del pañuelo verde explotó en Instagram. AUNO.Recuperado el 5/12/2020, de https://auno.org.ar/ probaste-el-filtro/

Peker, Luciana (2019). La revolución de las hijas. Buenos Aires: Paidós.

¿Qué redes sociales prefieren los argentinos según su edad?. Recuperado el 22/2/2021, de https:/www.digitalhouse. $\mathrm{com} / \mathrm{ar} /$ noticias/que-redes-sociales-prefieren-losargentinos-segun-su-edad-marketing

SAn Ildefonso, Jordi (2020). Todo sobre los filtros de Instagram Stories en 2020. Recuperado el 5/12/2020, de https:/culturon.es/nuevos-filtros-instagram-stories/

Sibilia, Paula (2017). La intimidad como espectáculo. Buenos Aires: Fondo de Cultura Económica.

Sibilia, Paula (2019). Cuerpo, subjetividad y tecnologías digitales. Culto al cuerpo como imagen: entre moralización y politización. Módulo de clase en el Seminario Cuerpos, subjetividad y tecnologías digitales. Maestría en Comunicación Digital Interactiva, Universidad Nacional de Rosario. Material de consulta para maestrandos/as. En https:// es.slideshare.net/MCDIUNR/unidad-4-cuerposubjetividad-y-tecnologas-digitales

Sierra Caballero, Francisco y Solá-Morales, Salomé (2020) Espacio público oposicional y ciberactivismo una lectura materialista de la acción conectiva. En Perspectivas de la Comunicación, Chile, volumen 13, N², pp.7-41. Recuperado el 22/2/2021, de http://revistas.ufro.cl/ojs/ 
index.php/perspectivas/article/view/2263

Situación digital, Internet y redes sociales Argentina 2020 (2020, abril 16). Xi Min Shu. Recuperado el 22/2/2021, de https:/yiminshum.com/social-media-argentina-2020/

Wodak, Ruth y Meyer, Michael (2003). Métodos de análisis crítico del discurso. Barcelona: Gedisa.

\section{Fuentes consultadas}

Alcaraz, María Florencia (2019, diciembre 11). Irreversible que sea ley: mandá aborto al 2020. La Tinta. Recuperado el 3/12/2020, de: https://atinta.com.ar/2019/12/irreversibleque-sea-ley-manda-aborto-al-2020/ Recuperado 5/12/2020 Cano, Sara (2020, febrero 25). El feminismo en 35 hashtags. Castellón Plaza. Recuperado el 22/2/2021, de https:// castellonplaza.com/el-feminismo-en-35-hashtags.

GutiéRrez, María Alicia (2019, junio 26). Marea Verde: la construcción de las luchas feministas en Argentina. La Tinta. Recuperado el 3/12/2020, de: https://atinta.com.

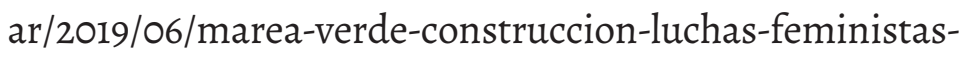
argentina/ Recuperado 5/12/2020

FundaCión HuÉsped. Historia del aborto en Argentina. Recuperado el 3/12/2020, de: https://www.huesped.org.ar/informacion/ derechos-sexuales-y-reproductivos/tus-derechos/ interrupcion-legal-del-embarazo/historia-del-aborto- enargentina/

ARbat, Sandra (2018, marzo 7). Por qué el color violeta es el verdadero símbolo de la marcha feminista del Día de la Mujer. La Vanguardia. Recuperado el 3/12/2020, de:https://www.lavanguardia.com/de-moda/ feminismo/20180306/441315715416/dia-mujer-8- marzohuelga-feminista-color-violeta.html

\#AbortoLegal: este es el significado del pañuelo verde https:// la100.cienradios.com/abortolegal-este-significado-delpanuelo-verde/ Recuperado 5/12/2020

El color verde en la gama Pantone: https:/ar.pinterest.com/ pin/289919294757459136/ Recuperado 22/2/2021

Instrucciones para usar el filtro $d$ e l pañuelo verde https://www.instagram.com/accounts/ login/ Recuperado 5/12/2020

La Nación ¿Qué simboliza el pañuelo verde? Recuperado el 3 de diciembre de 2020, de: https://www.lanacion.com. $\mathrm{ar} /$ sociedad/aborto-que-simboliza-el-panuelo-verde- 
nid2114538

La Nación Pañuelos verdes, celestes, naranjas y rojos: qué significa cada uno. Recuperado el 3 de diciembre de 2020, de: https://www.lanacion.com.ar/politica/abortopanuelos-verdes-celestes-naranjas-y-rojos- que-significacada-uno-nid2160587

Página/12 Del Encuentro Nacional de Mujeres de 2003 en Rosario al debate de hoy. El pañuelo verde, el símbolo. Recuperado el 3 de diciembre de 2020, de: https://www.paginai2.com. ar/121322-el-panuelo-verde-el-simbolo

¿Sabes qué significa el pañuelo verde a favor del aborto? Recuperado el 3 de diciembre de 2020, de: https://news. culturacolectiva.com/mundo/que-significa-el-panueloverde-a-favor-del-aborto-en-argentina/

Scarpini, E. Cuenta de Instagram https:/www.instagram.com/ ezescarpini/ Recuperado 22/2/2021

Torres, V. (2019, marzo 8). "Pañuelos, color y movimiento feminista en el \#8M 2019" Entrevista a Soledad Sosa. Recuperado el 3 de diciembre de 2020, de: https://youtu. be/o_uW40JBKXY

Torres, V. (2020, diciembre 3). Entrevista a militantes del PDT a través de WhatsApp. Grupo de WhatsApp: Mujeres PDTPO-Mendoza

Acerca de la continuidad de la lucha por el derecho al aborto. Recuperado el 3 de diciembre de 2020, de: https:// prensaobrera.com/opinion/acerca-de-la-continuidad-dela-lucha-por-el-derecho-al-aborto/

Conclusiones de la comisión de Mujeres y diversidades del XXVII Congreso del Partido Obrero. Recuperado el 3 de diciembre de 2020, de: https://prensaobrera.com/mujer/ conclusiones-de-la-comision-de-mujeres-y-diversidadesdel-xxvii-congreso-del-partido-obrero/

"Luchamos por este derecho como parte de la lucha contra toda explotación". Recuperado el 3 de diciembre de 2020, de: https://prensaobrera.com/politicas/luchamospor-este-derecho-como-parte-de-la-lucha-contra-todaexplotacion-2/

Fecha de recepción: 7 de diciembre de 2020 Fecha de aceptación: 18 de febrero de 2021

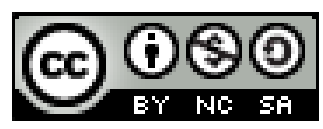

Licencia Creative Commons Atribución-No Comercial-Compartir Igual 4.0 Internacional 